\title{
VI. DIE PRINZESSIN VOR GERICHT
}

\author{
1. »Non si vedde mai tal tristezza universale« \\ Ein Mord und seine Folgen
}

Im Februar 1563 war Anna einunddreißig Jahre alt, seit über vierzehn Jahren verheiratet, und sie hatte wenige Monate zuvor ihrem siebten Kind das Leben geschenkt. Sie war Herzogin von Guise, Fürstin von Joinville, Marquise von Mayenne und Gräfin von Nantueil. Ihr Gemahl befand sich auf dem Höhepunkt seiner Macht. Es gab keine militärische Auseinandersetzung, die er nicht bestand; erst im Dezember hatte er die Schlacht von Dreux gewonnen und stand nun kurz davor, das belagerte Orléans einzunehmen. Anna genoß beträchtliches Ansehen bei Hofe, sie war befreundet mit der Königinmutter und mit allen großen Damen des Reiches. Zwar reiste sie viel und nahm Teil an den großen und kleinen Ereignissen des Hofes, sie lebte sonst aber ruhig, mal in den königlichen Schlössem, mal in Joinville und Nanteuil oder in ihrem Hôtel in Paris. Dann sollte ein Ereignis ihr Leben vollständig verändern.

\section{Das Attentat und seine unmittelbaren Auswirkungen}

Mitte Februar 1563 war Anna in Begleitung ihres ältesten Sohnes in der Nähe von Orléans angekommen, wo sie François zu treffen gedachte. Die Belagerung der Stadt näherte sich dem Ende. Ein Vorort war bereits eingenommen, der letzte Angriff auf die Hochburg der Hugenotten stand kurz bevor, und man verhandelte über einen Austausch von Geiseln zur Sicherung der Friedensgespräche. Gegen Abend erschienen einige Pagen vor der Herzogin mit der Nachricht, ihr Gatte befände sich auf dem Heimweg; sie solle die Tafel für das Nachtmahl decken lassen. Als François schließlich eintraf, bot er einen traurigen Anblick: Das Blut quoll ihm aus einer Wunde in Brust und Schulter. Ein Schuß war in der Dunkelheit auf ihn abgefeuert worden, und die Kugel hatte seinen Körper unterhalb des rechten Armes durchbohrt. Anna, qui n'attendoit rien moins que de le voir arriver en tel estat, brach in Tränen aus und mußte von dem Verwundeten getröstet werden. Die herbeigerufenen Ärzte schätzten die Verletzung zunächst als nicht tödlich ein: les chirurgiens qui sont près de luy promettent de le remettre bientost en santé, lautete die trügerische Hoffnung der Angehörigen ${ }^{1}$.

\footnotetext{
' Lancelot de Carles, Evesque de Riez, Lettre au Roy, contenant les actions et propos de Monsieur De Guyse, depuis sa blessure, jusques à son trespas, Paris 1563, in: Mémoires de Condé, Servant d'Éclaircissement et de Preuves à l'Histoire de M. de Thou, Contenant ce qui
} 
Sechs Tage später, am Vormittag des 24. Februar, nachdem die Chirurgen dem Patienten noch in einer schmerzhaften Operation zwei Kugeln und ein Stïck Draht aus der Wunde entfernt hatten, starb François. Zuvor hatte er gebeichtet und die Messe gehört und sich von den Mitgliedern seiner Familie verabschiedet. Der Bischof von Riez, Lancelot de Carles, der sich im Gefolge der Königinmutter an das Krankenbett des Herzogs begeben und diesem in seinen letzten Stunden Beistand geleistet hatte, beschrieb in einem Brief an den König die letzten Tage des Sterbenden, wobei er auch dessen Ansprachen an die Angehörigen nicht vergaß. Die Veröffentlichung dieses Berichts hat unter den Zeitgenossen nicht wenige Kontroversen ausgelöst. Die Rede, welche der Herzog seiner Gemahlin gehalten haben soll, ließ so viel Raum für Spekulationen hinsichtlich Annas ehelicher Treue, daß der Bischof gezwungen war, der ersten Druckfassung eine überarbeitete Version folgen zu lassen. Es ist nicht wahrscheinlich, daß der Sterbende, grandement travaillé de la fiebvre et de la sueur, tatsächlich die von Lancelot wiedergegebenen seitenlangen Ansprachen hielt, und es ist nicht festzustellen, was François seiner Gattin wirklich gesagt hat. Der Kardinal von Ferrara, Augenzeuge der Szene, berichtet zwar von der pietosa esortazione alla moglie et fig. ${ }^{l}$ des Herzogs, erwähnt aber lediglich die Aufforderung, di viver sempre fermi nella Religione cattolica et in obbedientia et servizio del $\mathrm{Re}^{2}$. In der ersten Fassung waren dem Herzog folgende Worte in den Mund gelegt worden:

Je ne veulx pas nyer que les conseils et fragilitez de la jeunesse, ne m'ayent quelquefoys conduict à choses dont vous avez peu estre offensée: je vous prie me vouloir excuser et me le pardonner, comme je vous pardonne: combien que mes offenses soient beaucoup plus grandes que les vostres, je ne me tiens pas des plus grans pecheurs en c'est endroict, ny aussi des moindres; mais depuis les trois derniéres années, vous sçavez bien avec quel respect $j$ 'ay conversé avecq vous, vous ostant toutes occasions de recepvoir le moindre mescontentement du monde ${ }^{3}$.

Der Satz "combien que mes offenses soient beaucoup plus grandes que les vostres « wurde für die zweite Fassung gestrichen, dafür war die Rede an manchen Stellen erweitert worden, so etwa um die Aussage, daß François seine Gemahlin stets geliebt und geschätzt habe, sans que nostre mutuelle amitié ait receu aucune diminution en tout le temps de nostre Mariage.

s'est passé de plus mémorable en Europe, Bd. 4, London 1743, S. 243-267, hier S. 246; Louis de Lorraine an Artus de Cossé, 21. Febr. 1563, Chartres, in: BnF, 500 Colb. 24, fol. 99r. Vgl. Occurences sent by Sir Thomas Smith, 26. Febr. 1563, in: Calendar Elizabeth, 1869, S. 162.

${ }^{2}$ RIEZ, Lettre au Roy, S. 252; Ippolito d'Este an Carlo Borromeo, 24. Febr. 1563, Dal campo presso Orleans, in: PACIFICI, Ippolito II d'Este, S. 434.

${ }^{3}$ Erste Ausgabe des Briefes, in: Mémoires de Condé, Bd. 4, S. 267. Das folgende Zitat: RIEZ, Lettre au Roy, S. 253. 
Die Reaktionen auf die indirekt gegen Anna erhobenen Vorwürfe waren so unterschiedlich wie ihre Autoren. Während die Rede des Herzogs vor allem von der Geschichtsschreibung des 19. Jahrhundert als 'Beweis` für ein schon vor seinem Tod bestehendes Verhältnis seiner Gemahlin mit ihrem zweiten Ehemann angesehen wurde, sprachen sich besonders protestantisch gesinnte Zeitgenossen energisch zugunsten der Tochter von Renée de France und gegen den Bischof und seinen als fort impertinent bezeichneten Brief aus ${ }^{4}$. Dabei ist weniger die Frage von Bedeutung, ob die Prinzessin ihrem Gemahl die eheliche Treue gehalten hat oder nicht, als vielmehr die Tatsache, daß Zweifel hieran offen geäußert werden konnten. Zwar hatte Lancelot seinen Text im Nachhinein abändern müssen, die Formulierungen waren zuvor aber an keiner Selbstzensur seitens des Kirchenmannes gescheitert. Zu Lebzeiten des Herzogs hätte sich der Bischof mit der Publikation zweideutiger Anspielungen über angebliche Liebesbeziehungen der Prinzessin sicher zurückgehalten. So zeigen die Ereignisse um den Brief vor allem, daß Anna trotz weitreichender Solidaritätsbekundungen der Herrscherfamilie und des Hofes angreifbar geworden war. Wenn die von den Guise mit Nachdruck vorangetriebene gerichtliche Verfolgung der für das Attentat Verantwortlichen in den folgenden Jahren in erster Linie der Ehre und dem Ansehen des Hauses dienen sollte, trug sie doch auch dazu bei, die Integrität der Witwe und ihre Treue für den Gemahl selbst nach dessen Tod unter Beweis zu stellen.

Die Trauer über den Tod des Herzogs von Guise war grenzenlos, und an den Höfen Europas flossen die Tränen lyke showers of rayne $e^{5}$ Während nach Florenz berichtet wurde, che non si vedde mai tal tristezza universale $[e]$ che la Reina mostra una passione come se mancasse la persona c'ha più cara al mondo, war in Ferrara zu erfahren, nicht nur der König, die Königin, die Kapitäne der Truppen und die Soldaten trauerten um den Herzog, sondern auch seine eigenen Feinde. Die Verzweiflung der Witwe war groß und allen offensichtlich: C'est pitie que de ceste pauvre dame, car jamays on ne veyt tel deuil et $\left[a\right.$ bien] besoin d'être consolée et conseillée en ses affayres ${ }^{6}$. Der Körper

${ }^{4}$ Für die erste Sichtweise: RUBLE, Assassinat, S. 48, für die zweite und das Zitat: BÈzE, Histoire Écclesiastique, Bd. 2, S. 270.

${ }^{5}$ Vom schottischen Hof: Thomas Randolph an William Cecil, 18. März 1563, Saint Andrews, in: Mark GREENGRASS, Mary, Dowager Queen of France, in: Michael LYNCH (Hg.), Mary Stewart. Queen in Three Kingdoms, Oxford, New York 1988, S. 171-194, hier S. 188, Anm. 5. Ein Exemplar der Schrift "The Regreit of the Duke of Guise deid", Paris 1563, befand sich in Maria Stuarts Besitz: Inventar der Bibliothek des Schlosses von Edinburgh, 1578, in: Julian SHARMAN, The Library of Mary Queen of Scots, London 1889, S. 63.

${ }^{6}$ Morte del duca di Guisa di archibusata, 27. Febr. 1563, in: ASF, MP 4850, fol. 195r; Giulio Alvarotti an Alfonso d'Este, 2. März 1563, Paris, in: FonTANA, Renata di Francia, Bd. 3, S. 77f.; Florimond Robertet an Jacques de Savoie, 25. Febr. (1563), Blois, in: Gustave BAGUENAULT DE PUCHESSE, Trois lettres inédites relatives à la mort du duc de Guise à Orléans, en 1563, in: Bulletin de la Société archéologique et historique de l'Orléanais 10 (1891-1894) S. 396-404, hier S. 400. Die Wörter in Klammern wurden von mir anhand 
des Toten wurde nach Joinville gebracht, sein Herz unter der Treppe des Hauptaltars von Notre-Dame in Paris beigesetzt. Bis zum Ende ihres Lebens sollte Anna hier oder in der Kirche des Augustinerklosters regelmäßig Messen für die Seele des Verstorbenen lesen lassen. Sie hatte den Sarg bis nach Blois begleitet und war dort mit zwei ihrer Schwäger und ihrem ältesten Sohn zurückgeblieben; die jüngeren Kinder waren bis zu diesem Zeitpunkt noch nicht über den Tod des Vaters unterrichtet. In Blois gedachte die Witwe, sich in ein abgelegenes Haus zurückzuziehen und vierzig Tage lang zu trauern. Ihre Freundin Katharina sorgte dafür, daß sie mit ihrem Gram nicht allein war und schickte die königlichen Prinzen und Prinzessinnen, die Trauernde zu besuchen. Erst dieses rituelle Sterben der Witwe, mit dem sie ihre Loyalität ihrem verstorbenen Gemahl gegenüber unter Beweis stellte, vollzogen, indem sie schwarze Kleidung anlegte und sich an einen einsamen Ort begab, sollte es Anna später ermöglichen, in das Leben zurückzukehren und die Verantwortung für ihre und für die Angelegenheiten ihrer Kinder zu übernehmen?

In ihrem Trauerdomizil empfing Anna zahlreiche Kondolenzschreiben. Bereits kurz nach dem Attentat, als François noch am Leben war, hatte sie Briefe erhalten, in denen ihr Trost und Beistand angeboten und versichert worden war, $\mathrm{da}$ Gott sein Leben erhalten würde, pour son service et pour la necessité de ce pauvre reaulme $e^{8}$. Nun bekundeten die Fürsten Europas ihr Beileid. Der Papst erinnerte die Witwe an die Pflichten einer sage et pieuse mère: Sie solle ihre Kinder so erziehen, daß sie in allem dem Vater glichen; sein Schreiben schließt mit der Hoffnung, que le regret d'avoir perdu vostre mary s'aille adouissant de plus en plus par la pieté et vertu de vos enfans'. Nur der König von Spanien konnte sich lange nicht entschließen, den Angehörigen des Verstorbenen, mit dem er einen mächtigen Mitstreiter im Kampf gegen die Feinde des Katholizismus verloren hatte, sein Beileid auszuspre-

BnF, Fr. 3180, fol. 62r korrigiert. Vgl. Ippolito d'Este an Alfonso d'Este, 24. (nicht 23.!) Febr. 1563, Dal campo presso Orleans, in: PACIFICI, Ippolito II d'Este, S. 431: Madama nostra di Guisa si trova tanto afflitta da questo caso, et sconsolata che è difficile a poterla confortare.

${ }^{7}$ Tomás Perrenot de Chantonnay und Francisco de Alava an Philipp II., 2. März 1563, Blois, in: Archivo documental Español. Negociaciones con Francia, Bd. 5, hg. v. der Real Academia de la historia, Madrid 1952, S. 97; Occurences in France, sent by Sir Thomas Smith, 3. März 1563, in: Calendar Elizabeth, 1869, S. 193; Giulio Alvarotti an Alfonso d'Este, 4. März 1563, Paris, in: FonTANA, Renata di Francia, Bd. 3, S. 86. Zu den Messen: Rechnungsbuch 1593-II (Febr., Apr., Juni). Vgl. Bernhard JUSSEN, Der Name der Witwe. Erkundungen zur Semantik der mittelalterlichen Bußkultur, Göttingen 2000, S. $273 \mathrm{f}$.

${ }^{8}$ Charles, Kardinal von Bourbon, an Anna d'Este, o.D. (Febr. 1563), in: BnF, 500 Colb. 24, fol. $167 \mathrm{r}$.

${ }^{9}$ Pius IV. an Anna d'Este, 15. Apr. 1563, Rom, in: OUdIN, Histoire, 5799, fol. 184v-185v. Vgl. die Briefe des Herzogs und der Herzogin von Urbino, 13. Mai 1563, Pesaro, in: BnF, Fr. 3180, fol. 89r u. MÜNCH (Hg.), Denkwürdigkeiten, S. 112f.; Thomas Randolph an William Cecil, 18. Mărz 1563, St. Andrews, in: Calendar Elizabeth, 1869, S. 211. 
chen. Monate später wurde Philipp schließlich von seinem Gesandten in Frankreich empfohlen, einige vordatierte Kondolenzschreiben zu verschicken, die, als sie endlich bei den Angehörigen ankamen, von großem Trost waren und empfangen wurden con lágrimas como el mesmo día que el buen Monsieur de Guisa fallesció ${ }^{10}$. Ende April war Anna zurück in Paris und empfing die Überbringer der Beileidsbekundungen persönlich, denen sie con pietà christiana, et con molta prudentia begegnete ${ }^{11}$.

\section{Die Zeit danach: Bemühungen zur Sicherung des Status}

Die Schwierigkeiten, denen sich die Prinzessin nach ihrer Rückkehr an den Hof zu stellen hatte, waren zunächst einmal finanzieller Art. François, ayant esgard au bon et loyal debvoir, fidélité, obéissance, honneur, révérence et cordiale amitie dont il a tousjours esté honoré, servy et respecté, hatte Anna zu seiner Universalerbin eingesetzt, unter der Voraussetzung allerdings, daß sie Witwe bliebe und nicht wieder heirate ${ }^{12}$. Die Bewunderung mancher Beobachter für den Reichtum der Guise darf jedoch nicht über die Tatsache hinwegtäuschen, daß der Herzog seiner Gattin Schulden in Höhe von rund 500000 Livre hinterlie $B^{13}$. Nicht nur Brantôme erzählt, François sei gestorben, wie er gelebt habe: chargé plus de debtes et de gloire, qu'il laissa à madame sa femme et à messieurs ses enfans, que de finances; die mit "Deniers venans des coffres de Madame pour employer en l'acquict des debtes de feu Monseigneur« betitelten Einträge im herzoglichen Rechnungsbuch des Jahres 1563 bestätigen diese Behauptung. So wurden von Anna endlich die confitures et autre marchandise bezahlt, mit denen ihr Gemahl Jahre zuvor den Herzog von Alba und dessen Begleiter bewirtet hatte, und sie beglich die Schulden ihrer letzten gemeinsamen Reise en Allemaigne. Auch für die hobsecques et funerailles des Verstorbenen, für draptz de deuil, für den service und die pauvres qui s'y sont trouvez wurde Geld ausgegeben, nicht zuletzt mußten die gentilz-

${ }^{10}$ Tomás Perrenot de Chantonnay an Philipp II., 31. Mai 1563, Paris, in: Archivo documental Español, Bd. 5, S. 258. Das Beileidschreiben, in dem der König die Witwe als mi muy cara prima bezeichnet: Philipp II. an Anna d'Este, 30. Apr. 1563, Madrid, in: Ibid. S. 527.

"'Marc' Antonio Barbaro an die Serenissima, 1. Mai 1563, Paris, in: SURIANo, BARBARO, Despatches, S. CXXIII.

${ }_{12}$ Testament von François de Lorraine, 24. Febr. 1563, in: BouILLÉ, Histoire, Bd. 2, S. $582 \mathrm{f}$.

${ }^{13}$ Giovanni Michiel, Relazione fur die Serenissima, 1561, in: TOMMASEO (Hg.), Relations, Bd. 1, S. 436. Die Zeitgenossen schätzten die Höhe der Schulden auf $400000-600000$ l.t.: Giulio Alvarotti an Alfonso d'Este, 3. Dez. 1563, Paris, in: ASM, Canc. duc., Amb. Francia 38. Denis CROUZET, Recherches sur la crise de l'aristocratie en France au XVI ${ }^{\mathrm{eme}}$ siècle: les dettes de la Maison de Nevers, in: Histoire, économie et société 1 (1982) S. 7-50, hier S. 9, spricht von 200000 1.t. Vgl. BoulLLÉ, Histoire, Bd. 1, S. 204, 240; CONSTANT, Guise, S. 52. 
hommes, paiges et aultres personnes estans à la conduicte du corps entlohnt werden ${ }^{14}$.

Daneben mußte Anna sich um die Angelegenheiten ihrer Kinder kümmern. Überzeugt davon, daß sie sich saigement et vertueusement verhalten würde, hatte François seiner Gemahlin testamentarisch die Verantwortung für ihre gemeinsamen Sprößlinge überlassen, was die Angehörigen als Zeichen seiner großer Liebe und Achtung ihr gegenüber deuteten ${ }^{15}$. Laut Bericht des Bischofs von Riez hatte der Herzog seine Gattin außerdem gebeten, den Kindern immer eine gute Mutter zu sein, während er dem ältesten Sohn Annas Wohl ans Herz gelegt habe, ainsi que Dieu et nature te le commandent: Er solle ihr gehorchen, honneur et revérťnce erweisen und ihren bons conseils et prudentes instructions folgen. Die Vormundschaft wurde der Prinzessin und ihren Schwägern Charles und Louis gemeinsam überschrieben. In seinem Beileidsschreiben forderte der Kardinal von Lothringen die Witwe auf: espousez voz petis enfans et leurs affaires, und versprach, so schnell wie möglich nach Frankreich zu kommen, um sie bei der Regelung ihrer gemeinsamen Angelegenheiten zu unterstützen. Tatsächlich sollten die beiden Kardinäle der Herzogin in den folgenden Jahren bei der Sorge um die Kinder betreffende Geschäfte zur Hand gehen, vor allem nach Annas zweiter Heirat, in deren Folge sie auf die Kuratel für ihre Sprößlinge aus erster Ehe verzichten mußte. Auch der Bruder in Ferrara wurde von ihr aufgefordert, de prandre mes affayres et de mes pauvres anfans an telle reccoumandations que $y^{\prime}$ an ay la fianse an vous, so daß in den Jahren nach dem Tod des Herzogs ein Block von Angehörigen um den Erbprinzen und seine Geschwister entstand, der den Vater und dessen Einfluß bei Hofe jedoch nur teilweise ersetzen konnte ${ }^{16}$.

Hinsichtlich ihres ältesten Sohnes hatte Anna einige wichtige Angelegenheiten zu erledigen, deren dringendste darin bestand, eine Geiselnahme des Knaben zu verhindern. Bereits im Dezember 1562 hatten die Reformierten einen Sohn des Herzogs von Guise als Garantie für ihre Sicherheit während der

${ }^{14}$ BRANTÔME, Euvres complètes, S. 188f.; Rechnungsbuch 1563, fol. 60r, 90r, 95r, $102 \mathrm{f}$. Vgl. auch die unter »Deniers payez par ledit trésorier en l'acquict des debtes de feu mondit seigneur « vermerkten Einträge, in: Ibid. fol. 84v. Das Fest für die Spanier fand 1559, die Reise ins Elsaß Anfang 1562 statt.

${ }^{15}$ Testament von François de Lorraine, 24. Febr. 1563, in: BoullLÉ, Histoire, Bd. 2, S. 583; Ippolito d'Este an Alfonso d'Este, 24. (nicht 23.!) Febr. 1563, Dal campo presso Orleans, in: PACIFICI, Ippolito II d'Este, S. 431. Die folgenden Zitate: RIEZ, Lettre au Roy, S. 254, 256.

${ }^{16}$ Konigliche Urkunde, die Charles und Louis de Lorraine sowie Anna d'Este als Tutoren und Kuratoren der Kinder des Herzogs von Guise einsetzt, 25. Sept. 1563, in: AST (Cast.), Int., PGN, cat. 5, m. 5, n. 6; Charles de Lorraine an Anna d'Este, 15. März 1563, Trient (wo sich der Kardinal beim Konzil aufhielt), in: LORRAINE, Lettres, S. 480. Der Brief wurde im selben Jahr in Lyon gedruckt. Anna d'Este an Alfonso d'Este, 25. Juni (1563), Paris, in: ASM, Canc. duc., Cart. prin. est. 1568 A/14. Vgl. Charles de Bourbon an Anna d'Este, o.D. (Mărz 1563), in: Eugène SAULNIER, Le rôle politique du cardinal de Bourbon (Charles X), 1523-1590, Paris 1912, S. 278f. 
Friedensgespräche verlangt, bis zum Zeitpunkt des Attentats war dieser Forderung aufgrund der Weigerung der Mutter jedoch nicht entsprochen worden, da Anna lieber selbst ins Lager der Feinde gehen wollte als den Sohn herauszugeben. Zwar soll sich François auf dem Sterbebett noch dazu bereit erklärt haben, den Prinzen nach Orléans zu schicken, sofern die Königin dies tatsächlich als notwendig für die Erlangung eines Friedens ansehe, doch nach seinem Tod setzte Anna alles daran, ihren Sohn zu beschützen. Ihre Bemühungen waren erfolgreich. Anfang März war klar, daß Henri nicht in das Lager der Feinde würde gehen müssen, visto lo que se habia hecho con el padre, und im Juni schickte seine Mutter ihn nach Joinville, da sie befürchtete, bei Hofe könne ihm algún desplacer zustoßen ${ }^{17}$.

Nicht minder großes Bemühen verlangte das Vorhaben der Herzogin, die Ämter und Würden des Vaters, das Gouvernement der Champagne etwa, dem ältesten Sohn übertragen zu lassen. Dabei ging es Anna und ihren Schwägern nicht nur um das Ansehen der Familie sondern auch um die mit diesen Aufgaben verbundenen Einkünfte. Problematisch gestaltete sich die Sicherung der grand maîtrise für Henri. Mit der Thronbesteigung Franz' II. hatte Anne de Montmorency das Amt an den Herzog von Guise abtreten müssen, nun, nach dessen Tod, forderte er es für seinen eigenen Sohn zurück. Aufgrund der Proteste des Konnetabel überließ die Königinmutter dem Prinzen von Joinville zunächst nur in voce alle Ämter, die sein Vater innegehabt hatte; hinsichtlich der schriftlichen Fixierung ihres Versprechens bat sie die Herzogin von Guise um etwas Geduld. Anna scheint daraufhin so nachdrücklich auf eine endgültige Entscheidung gedrängt zu haben, daß Katharina mehrmals beschwichtigend versichern mußte, sie werde ihr Wort halten. Im April endlich wurde der gerade dreizehnjährige Henri mit dem Amt des grand maittre versehen. Zu einer Entspannung des schwierigen Verhältnisses zwischen den Montmorency und den Guise konnte diese Entscheidung natürlich nicht beitragen. El Condestable está descontentisimo, schrieb der spanische Botschafter seinem König und berichtet, daß Montmorency die Herzogin weder besucht noch sich vor seiner Abreise vom Hofe von ihr verabschiedet habe, sondern regelrecht geflüchtet sei, um sie nicht zu sehen und nicht mit ihr sprechen zu müssen ${ }^{18}$.

Noch eine dritte Angelegenheit galt es im Namen des Prinzen von Joinville zu regeln, doch diesmal sollte Anna weniger erfolgreich sein. Jacques d'Albon, Maréchal de Saint-André, versprach einst dem ältesten Sohn des

${ }^{17}$ Marc' Antonio Barbaro an die Serenissima, 14. Jan. 1563, Paris, in: SURIANO, BARBARO, Despatches, S. XCV; RIEZ, Lettre au Roy, S. 248; Tomás Perrenot de Chantonnay und Francisco de Alava an Philipp II., 2. März 1563, Blois, in: Archivo documental Español, Bd. 5, S. 96; Perrenot an dens., 19. Juni 1563, Paris, in: Ibid. S. 291.

${ }^{18}$ Giulio Alvarotti an Alfonso d'Este, 2. März 1563, Paris, in: FonTANA, Renata di Francia, Bd. 3, S. 82; Katharina von Medici an Anna d'Este, Ende Febr. u. 31. März 1563, in: MÉDlCIS, Lettres, Bd. 1, S. 519, 553; Tomás Perrenot de Chantonnay an Philipp II., 12. Apr. 1563, Amboise, in: Archivo documental Español, Bd. 5, S. 172. 
Herzogs von Guise seine Tochter Catherine zur Frau. François hatte an diesem Projekt festgehalten, auch nachdem der Maréchal bei der Schlacht von Dreux gefallen war. Vor dem Tod des Herzogs von Guise waren die Verhandlungen so weit fortgeschritten, daß Catherine ihrer zukünftigen Schwiegermutter Anna bereits zur Erziehung übergeben worden war, und testamentarisch hatte François angeordnet, die Heirat voranzutreiben jusqu'à sa perfection et consommation. Die Witwe des Maréchal, Marguerite de Lustrac, hatte jedoch andere Pläne und forderte, obwohl Katharina von Medici sie daran erinnerte, $\mathrm{da} ß$ diese Verbindung dem Willen ihres verstorbenen Gemahls entspräche, ihre Tochter von den Guise zurück. Diese wiederum versuchten, das Mädchen nach Lothringen und mithin außer Reichweite der Mutter zu schaffen. Am Ende sollte Marguerite die Herausgabe ihrer Tochter erreichen, und die angedachte Hochzeit wurde nie gefeiert ${ }^{19}$.

Nicht zuletzt hatte die Herzogin von Guise nach dem Tod des Gemahls an ihre eigene Situation zu denken. Finanziell war sie über ihr douaire abgesichert, dieses galt es nun zu garantieren. Da zwischen der Witwe und der Familie des Verstorbenen Übereinstimmung herrschte und ihr niemand ihre Rechte streitig zu machen gedachte, war keine Eile geboten. Erst zweieinhalb Jahre nach dem Attentat wurde der »Accord fait par Monseigneur Le Cardinal de Lorraine et dame Anna d'Est duchesse de Guise pour la Jouissance de son douaire « unterzeichnet, und nach ihrer Vermählung mit dem Herzog von Nemours wurde das der Prinzessin Zustehende noch einmal per Vertrag fixiert. Die Guise garantierten ihr, die in ihrem Ehevertrag von 1548 gemachten Zusicherungen zu erfüllen, und sie versprachen, nach dem Tod von Antoinette de Bourbon, si madite dame de Nemours la survit, ihr douaire zu erhöhen, comme de raison ${ }^{20}$. Wie wohlwollend die Kardinäle von Lothringen und von Guise ihrer Schwägerin gesonnen waren, geht aus den Notizen hervor, welche Charles de Lorraine handschriftlich am Rand eines die Forderungen der Herzogin enthaltenden Papiers anbrachte. Trotz aller Einwände vermerkte er am Ende: je feray tousjours an tous androis trèshumble servisse à Madame ma seur, à laquelle je trouve raisonnable dès ceste heure assigner le tout an terre

${ }^{19}$ Testament von François de Lorraine, 24. Febr. 1563, in: BoulLLÉ, Histoire, Bd. 2, S. 583; Katharina von Medici an Anna d'Este, 26. März 1563, in: MÉDICIS, Lettres, Bd. 1, S. 545f.; Hubert Languet an August von Sachsen, 29. Juni 1563, Paris, in: Hubert LANGUET, Epistolae secretae ad principem suum Augustum sax. ducem, T. 3, hg. v. Johann Peter LUDwIG, Halle 1709, S. 247f.; Tomás Perrenot de Chantonnay an Philipp II., 22. Apr. u. 11. Nov. 1563, Paris, in: Archivo documental Español, Bd. 5, S. 193, 471; Thomas Smith an Elisabeth I., 20. Aug. 1563, Rouen, in: Calendar Elizabeth, 1869, S. 510; Charles de Lorraine an Anna d'Este, 22. Nov. 1563, Trient, in: LORRAINE, Lettres, S. 506.

${ }^{20}$ Der Vertrag vom 16. Okt. 1565 ist verzeichnet in: Inventaire général des titres (Pimodan), S. 408. Vertrag zwischen Charles und Louis de Lorraine auf der einen sowie Anna d'Este auf der anderen Seite, 26. Juni 1568, in: BnF, Fr. 8182, fol. 126r. Nach Antoinettes Tod wurden Anna zwecks Erhőhung ihres douaire die Einkünfte aus der Baronie Arzillières zugesprochen, vgl. den Vertrag vom 25. Mai 1584, in: Ibid. fol. 372f. 
à jouir par ces mains ${ }^{21}$. Sieben Jahre später bestätigte Annas ältester Sohn den ihr im Heiratsvertrag von 1548 zugesprochenen Besitz der Ländereien und Herrschaft von La Ferté-Bernard, und am selben Tag unterzeichneten Henri und seine Brüder eine Garantie für die Mutter, in Zukunft keine aus den Jahren ihrer Vormundschaft resultierenden Ansprüche stellen zu wollen ${ }^{22}$.

Annas Bemühungen nach dem Tod ihres Gemahls können als Versuch gewertet werden, sich selbst und ihrem Nachwuchs den Status zu sichern, welchen sie zu Lebzeiten des Herzogs genossen hatten. Interessant ist, daß die von ihr ergriffenen Maßnahmen genau den Hinweisen entsprechen, die Christine de Pizan in ihrem "Livre des Trois Vertus" für das korrekte Verhalten der Witwe gibt. Demnach solle sich eine kürzlich verwitwete Frau zunächst um das Testament des Verstorbenen kümmern, in einem nächsten Schritt Sorge für die Belange ihrer Kinder tragen und schließlich ihre eigenen Interessen vertreten, wobei auf jeden Fall darauf zu achten sei, daß ihre gerechten Ansprüche anerkannt würden ${ }^{23}$. Das Beispiel der Chrétienne d'Aguerre zeigt, daß die Verteidigung der Rechte ihres Nachwuchses nach dem Tod des Ehemannes für die Witwe tatsächlich an oberster Stelle stand. Chrétiennes zweiter Gemahl war 1586 gestorben, und die Prinzessin, die gerade ihrem letzten Kind das Leben geschenkt hatte, versammelte an ihrem Bett die Notare, um die ersten administrativen Schritte in die Wege zu leiten. Mit Zustimmung der Familie ließ Chrétienne sich vom König die Vormundschaft über ihre Sprößlinge bestätigen und machte sich anschließend sofort an die Verwaltung der Geschäfte ${ }^{24}$. Die Aufforderungen in den Beileidsschreiben an die Herzogin von Guise, fortan die Angelegenheiten ihres Nachwuchses zu vertreten, sind daher als Hinweis auf die Verantwortung zu sehen, welche Anna nun zu übernehmen hatte. Für die Zeit bis zur Mündigkeit der Kinder lag es in erster Linie an ihr und ihren Schwägern, bei Hofe die Interessen des Hauses zu vertreten. In diesem Zusammenhang ist auch die gerichtliche Verfolgung des Verbrechens durch die Witwe und ihre Familie zu sehen, ging es doch vor allem darum, die Verdienste des Ermordeten um Frankreich und die Krone nicht in Vergessenheit geraten zu lassen und somit für eine Kontinuität zu sorgen, von

${ }^{21}$ Madame de Nemours demande la jouyssance de ce dont cy apres est faicte mention, o.D. (1. H. 1568), in: AST, Int., PGN, cat. 2, m. 5, n. 9.

${ }^{22}$ Vertrag zwischen Henri de Lorraine und Anna d'Este, La Ferté-Bernard betreffend, und Garantie von Henri, Charles und Louis de Lorraine für die Mutter, 15. Mai 1575, in: AST (Cast.), Int., PGN, cat. 5, m. 5, n. 9; m. 6, n. 6. Weitere Verträge bezüglich Annas douaire, 6. Nov. 1574, 18. Dez. 1575, 30. Apr. 1602, in: BnF, Fr. 8182, fol. 130vf.; BoulLLE, Histoire, Bd. 3, S. 499f.; AN, m.c. VIII, 559, fol. 348f. Zum douaire der Witwe allgemein: Jacques POUMARÈDE, Le droit des veuves sous l'Ancien Régime (XVII-XVIII siècles) ou comment gagner son douaire, in: Danielle HAASE-DuBOSC, Éliane VIENNOT (Hg.), Femmes et pouvoirs sous l'ancien régime, Paris 1991, S. 64-76, hier S. 69f.

${ }^{23}$ PIZAN, Livre des Trois Vertus, S. 82-86.

${ }^{24}$ ALLAG, Chrétienne d'Aguerre, S. 58-60. Vgl. DIEFENDORF, Widowhood and Remarriage. 
der Henri und seine Brüder bei ihrem Eintritt in den Dienst für den König profitieren würden.

$\mathrm{Da}$ die Zeitgenossen das Bild der verwitweten Prinzessin, die ihre vaterlosen Kinder vor den Gefahren ihrer Umwelt schützt, im Gedächtnis behalten haben, zeigt ein das Attentat darstellender Druck, der in der Sammlung von Tortorel und Perrissin enthalten ist und als Reproduktion in großen Mengen verbreitet wurde. Am Fenster eines mit logis de monsieur de Guise nommé les Valins bezeichneten Gebäudes ist eine junge Frau zu sehen, die den Betrachter traurig anblickt und den neben ihr stehenden Knaben von der sich draußen abspielenden Szene abzuwenden sucht ${ }^{25}$. Von den Menschen in ihrer Umgebung wurde die junge Witwe als fahig und bereit angesehen, die Verantwortung für ihr eigenes und das Schicksal ihrer Kinder zu übernehmen. Voraussetzung hierfür war die Anerkennung ihrer Kompetenzen durch die Zeitgenossen, Kompetenzen, die sie in den vergangenen Jahren wiederholt unter Beweis gestellt hatte. So hatte François ihr die Verwaltung seines Besitzes, die Sorge für Ländereien, Vieh und Gebäude, die Ausfertigung von Urkunden und Verträgen sowie den Umgang mit Pächtern und Klienten überlassen, und Anna hatte sich bewährt. Sie hatte vom Vorbild ihrer Schwiegermutter gelernt, die sich als Witwe ebenfalls um die Geschäfte der Familie kümmerte und die junge Frau in ihre Aufgaben eingewiesen, ihr die Möglichkeiten und Grenzen ihres Handelns vor Augen gefuhrt hatte. Die >Ausbildung, der Prinzessin war so erfolgreich, daß Zweifel an Autorität oder Kompetenz der Witwe nicht aufkommen konnten. Hinzu kam, daß Anna ihrem Gemahl immer eine gute Ehefrau gewesen war, sie stets ein unantastbares Benehmen an den Tag gelegt und sich auch während der Zeit ihrer Trauer korrekt verhalten hatte. Folglich war zu erwarten, daß sie sich um den Nachwuchs und das Erbe ihres Gatten verantwortungsvoll kümmern würde, womit die Voraussetzungen für eine Übernahme eines großen Teiles der Verantwortung durch die junge Witwe erfüllt waren ${ }^{26}$.

${ }^{25}$ Jacques TORTOREL, Jean PERRISSIN, Les grandes scènes historiques du XVI siècle. Reproduction fac-similé du recueil, hg. v. Alfred FranKLIN, Paris 1886, Nr. 27. Eine Abb. in: The French Renaissance in Prints from the Bibliothèque Nationale de France, Kat., Los Angeles 1994, S. 412.

${ }_{26}$ Vgl. Scarlett Beauvalet-BoutouYRIE, Être veuve sous l'Ancien Régime, Paris 2001, S. 219-223; Eliane VIENNOT, Veuves de mère en fille au XVI siècle: Le cas du clan Guise, in: Nicole PELlEgRIN, Colette H. WINN (Hg.), Veufs, veuves et veuvage dans la France d'Ancien Régime, Paris 2003, S. 187-198, hier S. 187f. 


\section{2. »Nous l'oublions jamais« - Rache und Gerechtigkeit}

Das erste Wort, welches nach dem Anschlag auf François de Lorraine gesprochen wurde, war »Rache«. Katharina von Medici versicherte dem Bruder des Verwundeten gleich am Tag nach dem Attentat: je meteré tout set que j'é au monde et de crédist et de puisance pour $m$ 'en vanger, et suis seure que Dieu me le pardonnera, und nach dem Tod des Herzogs wurde der Ruf nach Rache nur noch lauter. Se qui nous reconforte le plus sait [c'est] l'asuranse que nous avons que punires les maleureus et mechant qui an sont cose, schrieb die Herzogin von Lothringen ihrer Mutter und fugte hinzu: nous l'oublions jamais $^{27}$. Die einzigen, die nicht in den Ruf nach Rache einstimmten, waren die Angehörigen des Ermordeten. Ließ Brantôme die Witwe auch ausrufen: Dieu! si tu es juste, comme tu le dois estre, vange cecy; autrement..., so ist doch in keinem Brief und in keiner der unzähligen Aufrufe, Bitten und Eingaben, die Anna und ihre Familie in den folgenden Jahren dem König und seinen Parlamenten präsentieren sollten, von Rache oder Vergeltung die Rede, immer wird nur justice, Recht und Gerechtigkeit, gefordert. Auf welch penetrante Art und Weise die Prinzessin dem Herrscher und seiner Mutter gegenüber auf das ihr zustehende Recht pochte, ist an dem Hinweis zu erkennen, mit dem Katharina die Freundin während der Auseinandersetzung um die Tochter des verstorbenen Maréchal de Saint-André von ihrer Position zu überzeugen suchte: Wer Gerechtigkeit wolle, müsse selbst auch gerecht sein - volendo lei giustitia, la deve far ancor $l e i^{28}$.

${ }^{27}$ Katharina von Medici an Louis de Lorraine, 19. Febr. 1563, in: MÉDICIS, Lettres, Bd. 1, S. 512; Claude de Valois an Katharina von Medici, o.D. (Ende Febr.-Anfang März 1563), in: BnF, Fr. 6609, fol. 29r.

${ }^{28}$ BRANTÓME, Recueil des Dames, S. 706, der wohl der Darstellung in: RIEZ, Lettre au Roy, S. 247 folgt, wo ebenfalls zu lesen ist: elle en demandoit vengence à Dieu. Giulio Alvarotti an Alfonso d'Este, 15. Okt. 1563, Paris, in: ASM, Canc. duc., Amb. Francia 38. Zum Ruf der Guise nach »justice«: Tomás Perrenot de Chantonnay an Philipp II., 22. Apr. 1563, Paris, in: Archivo documental Español, Bd. 5, S. 187; Discours sur la mort du duc de Guise, o.D. (Ende Sept. 1563), in: BnF, Fr. 17305, fol. 17v; Giulio Alvarotti an Alfonso d'Este, 23. Nov. u. 3. Dez. 1563, Paris, in: ASM, Canc. duc., Amb. Francia 38; Michel de CASTELNAU, Mémoires, hg. v. Claude-Bernard PETITOT, Paris 1823, S. 318. Dagegen spricht Jules GASSOT, secrétaire du roi, Sommaire mémorial (souvenirs) (1555-1623), hg. v. Pierre CHAMPION, Paris 1934, S. 98 von "vengeance». Zum Begriff: Andrea GRIESEBNER, Martin SCHEUTZ, Herwig WEIGL (Hg.), Justiz und Gerechtigkeit. Historische Beiträge (16.-19. Jahrhundert), Innsbruck u.a. 2002; Paolo PRODI, Una storia della giustizia. Dal pluralismo dei fori al moderno dualismo tra scienza e diritto, Bologna 2000. 


\section{Das Problem der Vendetta \\ und die komplizierte Suche nach den Schuldigen}

Der Wunsch, das Verbrechen nicht ungesühnt zu lassen und den Täter ohne Verzug seiner als gerecht angesehenen Strafe zuzuführen, wurde am deutlichsten von den Soldaten des Herzogs und von seinen Anhängern aus den unteren Reihen des französischen Adels artikuliert. Die Erstürmung des belagerten Orléans schien näher denn je, da sich die Männer des Verstorbenen entschlossen zeigten, entweder die Stadt einzunehmen, um den Tod ihres Führers zu rächen, oder zu sterben. Beschreibungen des nach der Eroberung des Ortes zu erwartenden Szenarios lassen die Ereignisse erahnen, die das Königreich im August 1572 erschüttern sollten: gridano tutti vendetta, vendetta, et dicono volerla fare di modo che non se ne udì mai più tale, berichtete der ferraresische Gesandte, und im Falle einer Einnahme Orléans' fariano una mortalità così grande che non se n'è forsi mai più udita una tale ${ }^{29}$. Der Gedanke der Vendetta verbreitete sich in Windeseile im Lager der Guise. Wenige Monate nach dem Anschlag unterzeichnete einer der Klienten der Familie das Versprechen, dem neuen Herzog, dessen Onkeln und Mutter getreulich zu dienen, pour vanger la mort dud[it] feu Mons' de Guize jusques a le quarte generatioin $^{30}$.

Die Königinmutter befand sich in einer schwierigen Situation. In dem Bewußtsein, ein derartiges Verbrechen nicht ungesühnt lassen zu können, war sie eine der ersten gewesen, die Vergeltung gefordert hatten. Doch was Katharina vor allem wollte, war Frieden, und so versuchte sie, beide Ziele gleichermaßen voranzutreiben, ein Bemühen, das nach Einschätzung der Beobachter erfolglos bleiben müsse, perchè chi desidera la vendetta non può di ragione cercar con tanta instancia la pace ${ }^{31}$. Allen Prognosen zum Trotz gelang der Königinmutter beides. Einen Monat nach der Tat wurde der mittlerweile gefaßte Attentäter, ein Mann namens Jean de Poltrot, auf grausame Weise hingerichtet, squartato à coda di quattro Cavalli et poi infine squartato vivo con uno coltellazzo, non havendo li Cavalli potuto squartarlo, womit der Forderung nach Rache zunächst einmal Genüge getan war. Zur gleichen Zeit wurde in Am-

${ }^{29}$ Giulio Alvarotti an Alfonso d'Este, 2. u. 4. März 1563, Paris, in: FonTANA, Renata di Francia, Bd. 3, S. 77, 86. Vgl. Ippolito d'Este an Carlo Borromeo, 24. Febr. 1563, Dal campo presso Orleans, in: PACIFICI, Ippolito II d'Este, S. 433.

${ }^{30}$ Versprechen von Guy de Daillon, 16. Aug. 1563, in: Mark GREENGRASS, Functions and limits of political clientelism in France before Cardinal Richelieu, in: Neithard BULST u.a. (Hg.), L'État ou le roi. Les fondations de la modernité monarchique en France (XIV ${ }^{e}-X^{\prime}{ }^{e}$ siecles), Paris 1996, S. 69-82, hier S. 79.

${ }^{31}$ Marc' Antonio Barbaro an die Serenissima, 8. Mărz 1563, Paris, in: SURIANO, Barbaro, Despatches, S. CVI. 
boise das Friedensedikt unterzeichnet ${ }^{32}$. Natürlich begnügten sich die Parteien weder mit einem wenig stabilen Frieden noch mit der Hinrichtung eines Mannes. Die Guise, überzeugt, daß es sich bei dem Mörder nicht um einen Einzeltäter handeln könne, wollten die wahren Verantwortlichen zur Rechenschaft gezogen sehen. Nachdem Anna sich zur Trauer nach Blois zurückgezogen hatte, verließen ihre Schwäger den Hof, entschlossen, vom König Gerechtigkeit zu fordern, et si l'on ne leur veult faire, ce qu'est tout certain, je ne sçay ce que en succédera ${ }^{33}$.

Jean de Poltrot beschuldigte in dem nach seiner Festnahme durchgeführten Verhör Gaspard de Coligny, ihn zu seiner Tat angestiftet zu haben: il feroit un ceuvre meritoire envers Dieu et envers les hommes, soll dieser ihn ermutigt haben, während Theodore de Bèze und ein weiterer Prediger ihm derart den Kopf verdreht hätten, daß er bereit gewesen sei, alles furr sie zu tun. Pasquier beurteilte diese Aussagen, welche von vielen als assez variables angesehen wurden: Si cela est vray ou non, je m'en rapporte à ce qui en est ${ }^{34}$. Tatsächlich widerrief Poltrot vor seiner Hinrichtung das Geständnis teilweise und veränderte dessen Gehalt. Doch fur die Guise und ihren Kampf um Gerechtigkeit waren die Ergebnisse der Verhöre zweitrangig, da für sie die Verantwortlichen bereits feststanden. Neben Coligny als dem Hauptschuldigen richteten sich die Vorwürfe gegen den Prinzen von Condé, obwohl dieser von Poltrot sogar entlastet worden war, während Théodore de Bèze trotz seiner eminenten Rolle bei der angeblichen Überzeugung des Attentäters weniger interessant erschien, wohl wegen der offensichtlichen Unglaubwürdigkeit der ihn betreffenden Aussagen. Ob der Mord am Herzog von Guise tatsächlich von Coligny, Condé oder anderen reformatorisch Gesinnten in Auftrag gegeben worden war oder ob persönliche Motive des Einzeltäters Poltrot in Verbindung mit dem aufgeheizten politischen Klima des ersten Religionskrieges verantwortlich gemacht werden müssen, bleibt derweil unklar.

${ }^{32}$ Giulio Alvarotti an Alfonso d'Este, 20. März 1563, Paris, in: FonTANA, Renata di Francia, Bd. 3, S. 89. Vgl. Marc' Antonio Barbaro an die Serenissima, 23. März 1563, Paris, in: SURIANO, BARBARO, Despatches, S. CXIf.

${ }^{33}$ Tomás Perrenot de Chantonnay an Philipp II., 13. März 1563, Blois, in: Mémoires de Condé, Bd. 2, S. 142.

${ }^{34}$ L'Interrogatoire et deposition faicte a un nommé Jehan de Poltrot, soy disant seigneur de Merey, sur la mort de feu monsieur le duc de Guyse, Paris 1563, in: Variétés historiques et littéraires. Recueil de pièces volantes rares et curieuses en prose et en vers, Bd. 8, hg. v. Edouard FOURNIER, Paris 1857, S. 5-29, hier S. 8, 13f.; Brief Discours de tout ce qui a esté négotié pour la quérelle qui est entre les Maisons de Guyse et de Chastillon, depuis l'Edit de Pacification des troubles naguéres survenus en ce Royaume, jusques au huitieme jour de Janvier, mil cinq cens soixante-trois. M.D.LXIIII, in: Mémoires de Condé, Servant d'Éclaircissement et de Preuves à l'Histoire de M. de Thou, Contenant ce qui s'est passé de plus mémorable en Europe, Bd. 5, London 1743, S. 17-40, hier S. 19; Estienne PASQUIER, Lettres historiques pour les années 1556-1594, hg. v. Dorothy THICKETT, Genf 1966, S. 127. Vgl. Nicola M. SUTHERLAND, The Assassination of François Duc de Guise, February 1563, in: The Historical Journal 24 (1981) S. 279-295. 
In einer ersten Antwort auf die Aussagen Poltrots, veröffentlicht noch vor dessen Hinrichtung, wies Coligny die gegen ihn erhobenen Vorwürfe zurück. Die Gemahlin des Herzogs habe er wiederholt vor Mordanschlägen gegen ihren Gatten gewarnt, schreibt der Admiral, und auch Condé behauptete, Anna mehrere Briefe geschrieben zu haben, à ces fins que laditte dame taschast à le retirer de son entreprinse et de la poursuitte qu'il faisoit contre luy et ceux de la religion ${ }^{35}$. Colignys Forderung, den Attentäter bis zum Friedensschluß sicher zu verwahren, um dann eine Gegenüberstellung zu ermöglichen, wurde nicht entsprochen. Angeblich um Tumulten vorzubeugen, aber auch, weil la garde de tel homme n'apportera aucun proufict, mußte die Hinrichtung vor Ankunft der sterblichen Überreste des Herzogs in Paris vollzogen sein. Die Klärung der Tatsachen war somit von Anfang an unmöglich gemacht ${ }^{36}$. In der Zeit zwischen April 1563 und Januar 1566 sollten Anna und ihre Angehörigen dann die Verfolgung der in ihren Augen fur das Attentat Verantwortlichen betreiben. Dabei bedienten sie sich einer Mischung aus Unterwerfungs- und Machtgebaren und untermauerten die von der Witwe und den Waisen vorgetragenen Forderungen nach justice mit der Präsenz ihrer waffentragenden Parteigänger.

\section{Nachdruck und Nachgiebigkeit Strategien für die Verfolgung der Tat}

Ende April 1563, nachdem Annas Trauerzeit abgeschlossen und sie nach Paris zurlickgekehrt war, begann der Druck auf Katharina von Medici zu wachsen. Von Italien aus bat Charles de Lorraine die Fürsten Europas, das Anliegen der Guise am französischen Hof zu unterstützen, und der Herzog von Aumale begab sich in die Hauptstadt, per riscaldare questo Parlamento. Die Witwe selbst richtete ein Gesuch an die Königin und forderte ihre Besucher auf, die Herrscher zu bitten, che li fusse fatta justitia di un tradimento tale usato a suo marito. Daneben verbreiteten Anna und ihre Schwäger das Gerlicht, ihre Personen seien der Gefahr weiterer Attentate ausgesetzt. Vier Männer hätten sich auf den Weg nach Italien gemacht, um den Kardinal von Lothringen umzubringen, erzählte Anna dem venezianischen Gesandten, und auch sie selbst befande sich in Gefahr: hora la fanno minacciare di tossicarla se non la si

${ }^{35}$ HATON, Mémoires, Bd. 1, S. 396. Vgl. Colignys "Response à.l'interrogatoire«, in: Interrogatoire et deposition, S. 12, Anm. 2, und seinen Brief an Katharina von Medici, 12. März (1563), Caen, in: MÜNCH, Erinnerungen, Bd. 1, S. 292-295.

${ }^{36}$ Jean du Tillet an Katharina von Medici, 17. Marz 1563, Paris, in: BnF, Fr. 6615, Nr. 41. 
aquieta, et che non procedi più inanti, ma che lei spera in Dio, et nel Re che le sarà fatta iustitia ${ }^{37}$.

Nachdem sich der Admiral im Mai ein zweites Mal gerechtfertigt und Louis de Bourbon gemeinsam mit François d'Andelot seine Unschuld vor dem Rat des Königs beschworen hatte, verbot Karl IX.

à Madame la Duchesse Doüairiere de Guise, veufve dudit deffunt, enfans, freres, parens et amis; comme aussi au Seigneur de Chastillon, Admiral de France, enfans, freres, parens et amis, qu'ils n'ayent par eux ny par leurs gens et serviteurs, à s'offenser ne faire offencer les uns les autres, par voye de fait et de force ou autrement ${ }^{38}$.

Zur Entspannung der Situation trug dieser Erlaß des Königs jedoch keineswegs bei, und die Angst vor weiteren Attentaten grassierte in beiden Lagern. Während man in Venedig erfuhr: ad essa Mad" di Guisa sono posti inanti diversi spaventi di mali che le potriano avenire, interessierte man sich am englischen Hof eher für das Wohlergehen des Admirals, welcher befüchtete, $\mathrm{daß}$ einer der vielen waffentragenden Männer bei Hofe auf ihn schießen könn$t^{39}$. Katharina von Medici war wieder einmal damit beschăftigt, die Gemüter zu beruhigen, und wieder einmal scheint es vor allem ihre Freundin Anna gewesen zu sein, die sie mit allen Mitteln zu überzeugen suchte, Geduld zu haben ${ }^{40}$. Die Witwe wollte sich mit den Zusicherungen der Konigin jedoch nicht zufriedengeben und betrieb gemeinsam mit den Schwägern die Mobilisierung ihrer Parteigänger. So wird etwa der Hinweis auf ein Fest erklärbar, welches Anna in jener Zeit im Hôtel de Guise gab. Bei diesen Festen versammelten sich die Anhänger der Familie, die Stimmung wurde angeheizt, und im Anschluß begab man sich, wie ein Augenzeuge berichtet, mit großem Gefolge an den Hof: Il Cardinal di Guisa, Madama et Monsr. di Guisa si sono trattenuti questi due giorni qui in Parigi, et hora appunto scrivendo, sono passati tutti 3 sotto alle mie finestre et se ne vanno in Corte con una straordinaria e grossa compagnia di molti cavalli ${ }^{41}$.

${ }^{37}$ Marc' Antonio Barbaro an die Serenissima, 21. Apr., 1. u. 27. Mai 1563, Paris, in: SURIANO, BARBARO, Despatches, S. CXIX, CXXIIIf., CXXX. Annas an den spanischen König gerichtete Bitte um Unterstiltzung: Tomás Perrenot de Chantonnay an Philipp II., 25. Mai 1563, Paris, in: Archivo documental Español, Bd. 5, S. 253.

${ }^{38}$ Beschluß des königlichen Rates, 16. Mai 1563, in: Du BoucheT, Preuves de l'Histoire de l'illustre Maison de Coligny, Paris 1662, S. 537. Die Rechtfertigung Colignys: Mémoires de Condé, Bd. 4, S. 339f. Die Versicherungen Condés und Andelots: Brief Discours, S. 20-22.

${ }^{39}$ Marc' Antonio Barbaro an die Serenissima, 27. Mai 1563, Paris, in: SURIANO, Barbaro, Despatches, S. CXXXI; Thomas Smith an Elisabeth I., 11. Mai 1563, Poissy, in: Calendar Elizabeth, 1869, S. 334.

${ }^{40}$ Katharina von Medici an Anna d'Este, Anfang Mai (nicht März-April!) 1563, in: MÉDICIS, Lettres, Bd. 10, S. 97.

${ }^{41}$ Marc' Antonio Barbaro an die Serenissima, 13. Juni 1563, Paris, in: SURIANO, BARBARO, Despatches, S. CXXXV. Der Hinweis auf das Fest: Rechnungsbuch 1563, fol. 78vf. (Juni). Wohin die Aufwiegelung des Pariser Volkes fuhren konnte, wird aus einem Brief Katharinas 
So zeichnete sich schon zu Beginn der Bemühungen der Witwe zur Verfolgung der für den Tod ihres Gemahls Verantwortlichen eine Strategie ab, die auch in den folgenden Monaten und Jahren erkennbar bleibt: die abwechselnde oder teilweise auch gleichzeitige Bekundung von Stärke und Schwäche. Auf der einen Seite stilisierte sich die Prinzessin durch die Verbreitung des Gerüchts, sie und ihre Angehörigen seien der Gefahr weiterer Anschläge ausgesetzt, zum schutzlosen Opfer, welches all seine Hoffnung in Dio, et nel Re setze und dennoch zum zweiten Mal zum Opfer zu werden drohe, auf der anderen Seite widerspricht die offensive Werbung um Unterstützung - selbst Maria Stuart und Philipp II. förderten ihr Vorgehen - und die Zurschaustellung von Stärke durch Auftritte bei Hofe mit großem Gefolge diesem Bild ${ }^{42}$. Ob Anna tatsächlich Morddrohungen erhalten hat, kann anhand von Quellen nicht nachgewiesen werden. Die Tatsache aber, daß sie die Regierungen auBerhalb Frankreichs über diese fiktiven oder realen Drohungen unterrichtete, zeigt, daß sie ihre vorgebliche Schwäche zu nutzen gedachte. Ein Vergleich mit den Frauen, die sich während der Religionskriege in Dijon als Botinnen, Spioninnen oder dergleichen betätigten, zeigt, daß die vorgebliche weibliche Unwissenheit, Ignoranz und Hilflosigkeit vor Gericht tatsächlich zur Verteidigung konkreter politischer Handlungen benutzt wurde, wie etwa von Gasparde de Montholon, die in einem Verhör ihre Taten als boutade de femme bezeichnete. Gleichzeitig jedoch demonstrierte Anna d'Este gemeinsam mit ihren Verwandten, daß sie auch vor der Anwendung von Gewalt nicht zurückschrecken würde, etwa als sie den Hof im Sommer 1565 in Begleitung von siebenhundert Reitern verlie $\beta^{43}$. Wie überzeugend die Machtgebärden der Guise waren, geht aus dem zitierten Friedensgebot Karls IX. hervor. Daß auch die Prinzessin der Gruppe derer zugerechnet wurde, die zu einem friedvollen Vorgehen ermahnt werden mußten, sie mithin keineswegs schutz- und hilflos war, ist letztlich an der Plazierung ihres Namens an erster Stelle dieses Erlasses zu erkennen. Drei Ereignisse verraten, auf welche Weise sich die Witwe und ihre Angehörigen dieser doppelten Strategie bedienten.

von Medici an Marguerite de Valois, Herzogin von Savoyen, 11. Juni 1563, ersichtlich, in: MÉDICIS, Lettres, Bd. 2, S. 56f.

${ }^{42}$ Marc' Antonio Barbaro an die Serenissima, 1. Mai 1563, Paris, in: SURIANo, Barbaro, Despatches, S. CXXIV; Jean Ébrard an Katharina von Medici, 8. Juli 1563, in: SAINTSULPICE, Ambassade en Espagne, S. 136.

${ }^{43}$ Francisco de Alava an Philipp II., 5. Aug. 1565, Cognac, in: Archivo documental Español, Bd. 8, S. 36. Das Zitat aus dem Verhör der Gasparde de Montholon, 23. Juli 1592, in: FINLEY-CROSWHITE, Engendering the Wars, S. 152. 


\section{Meulan}

Im Sommer 1563 schien sich die Lage zu entspannen. Der Prăsident des Pariser Parlaments konnte die Königinmutter beruhigen, die vergangenen zwei Wochen seien die friedlichsten der letzten hundert Jahre gewesen, doch sollte dies nur die Ruhe vor dem Sturm sein. Die Guise planten, ihr Anliegen Karl IX. mit weitaus größerem Nachdruck vorzutragen, als sie es bisher getan zu haben meinten. Seit Mitte September erwarteten daher Anna und ihr ältester Sohn, ihre Schwäger Claude und René sowie der Graf von Vaudémont den König in Saint-Denis. Doch erst ein Brief Katharinas, in dem sie der Herzogin ihre Genesung nach einem Reitunfall mitteilte, gab das Zeichen zum Aufbruch ${ }^{44}$.

Am Nachmittag des 26. Septembers 1563, einem Sonntag, präsentierte sich die Familie des Ermordeten mit einigen ihrer Parteigänger in der Kirche von Meulan, wo Karl an der Vesper teilgenommen hatte. Ils sont en délibération, quant ilz iront trouver le roy, de laisser tous les valletz et menuz gens, et s'accompaigner des gens de liste, affin de ne monstrer la suytte si grande que le bruict en a esté, war Montmorency zuvor von einem seiner Spione informiert worden, und tatsächlich sollte der Spott der hugenottenfreundlichen Kommentatoren die Guise ob der geringen Zahl ihrer Anhängerschaft nicht verschonen: quelque peine qu'ils eussent mis d'assembler gens, leur trouppe estoit au reste assez petite, sans les soldatz levez pour leur garde ${ }^{45}$. Doch die Rechnung der Witwe und ihrer Angehörigen, die ein aggressives Auftreten verhindern, sich vielmehr als trauernd und wehrlos darstellen wollten, ging auf. Der König, selbst noch ein halbes Kind, fühlte sich durch den Auftritt der Guise nicht bedroht, sondern vielmehr an seine Pflichten als Beschutzer der Witwen und Waisen erinnert. Gemeinsam mit dem Kardinal von Bourbon, den Herzögen von Montpensier, Nemours und Longueville sowie dem Prince dauphin d'Auvergne fielen die Angehörigen des Ermordeten vor Karl auf die Knie. Antoinette war es, welche sprach und die Bittschrift der Hinterbliebenen uberreichte: chose trop honteuse et ignominieuse sei es demnach fur sie und ihre Nachkommen, et pouroient estre tenuz deffaillans du debvoir que nature, les loix de Dieu et des hommes tant Chrétiens que infidelles, mesmes le sens commung et naturel leur commande, wenn sie länger zögerten, und da, wie es weiter heißt,

les dictz suppliantz ont cest honneur de vous appartenir, Sire, de parenté, que le deffunct, son filz aisné et deux desdictz freres sont Pairs de France, que Vostre Majesté a de dieu la

${ }^{44}$ Christophe de Thou an Katharina von Medici, 13. Aug. 1563, Paris, in: BnF, Fr. 6615, fol. 36r; Katharina von Medici an Anna d'Este, Ende Sept. 1563, in: MéDICIS, Lettres, Bd. 2, S. $98 \mathrm{f}$.

${ }^{45}$ Ein unbekannter Informant an Anne de Montmorency, 19. Sept. 1563, Paris, in: BnF, Fr. 3157, fol. 142r; Brief Discours, S. 23f. 
protection des Vefves et Pupilles oultraigés et affligez, et devez Justice à tous voz subjectz, il vous plaise, en icelle administrant Justice, permectre à iceulx suppliants faire dès maintenant poursuytte de la vuidicté et réparation dudict faict, en tel lieu et par davant tel de voz Juges que le droict, les loix, voz edictz et ordonnances le portent ${ }^{46}$.

Wăhrend der gesamten Zeremonie habe man in der Kirche nur die Seufzer und das Schluchzen der Anwesenden gehört, war dem spanischen Botschafter zugetragen worden, und tatsächlich zeigte sich der König erschüttert: Il me semble avoir ouy dire que Dieu faisoit régner les Roys par la Justice, antwortete er der Witwe, [et] pour ce, voulx-je qu'elle soit ouverte et faicte si bonne, que Dieu et le monde en demeurent satisfaict, et que ma conscience en soit deschargée. Noch am selben Tag händigte er den Guise die schriftliche Erlaubnis aus, den Mord gerichtlich zu verfolgen ${ }^{47}$.

Was wie eine spontane, aus einem Gefuhl verletzter Gerechtigkeit heraus entstandene Handlung erscheint, war in Wirklichkeit eine gut abgestimmte, sich auf historische Prăzedenzfalle berufende Aktion. So sind nicht nur unter den Statthalterinnen in den spanischen Niederlanden Fürstinnen zu finden, die sich aus Gründen des Machterhalts bewußt als Witwen inszenierten, auch in Annas unmittelbarem Umfeld gab es zahlreiche Damen, die selbst bereits an vergleichbaren Aktionen teilgenommen hatten, darunter auch Katharina von Medici $^{48}$. Bei Kniefällen handelt es sich darüber hinaus um eine besonders ausdrucksstarke Form ritueller Kommunikation, die nur in Grenzfällen und zur Klärung grundsätzlicher Fragen angewendet wurde, wie Beispiele aus Oberösterreich und der Steiermark zeigen. Dort reagierten die Landesherren auf die Kniefälle ihrer Untertanen mit Schrecken und Ärger. Ich bin nicht Gott, dass Ir mich anbeten sollet, soll Erzherzog Karl gerufen und mit dem Abbruch der Audienz gedroht haben, aber letztendlich gab er dem Anliegen seines Adels

${ }^{46}$ Gesuch der Guise an Karl IX., 26. Sept. 1563, in: Mémoires de Condé, Bd. 4, S. 667f. Das Zitat muBte von mir anhand BnF, Fr. 20461, S. 101 an so vielen Stellen korrigiert werden, daß diese nicht im Einzelnen gekennzeichnet sind. Bei dem "prince dauphin d'Auvergne« handelt es sich um François de Bourbon, Sohn des Herzogs von Montpensier.

${ }^{47}$ Tomás Perrenot de Chantonnay und Francisco de Alava an Philipp II., 30. Sept. 1563, Paris, in: Archivo documental Español, Bd. 5, S. 421; Mündliche Antwort und Dekret Karls IX., 26. Sept. 1563, in: Mémoires de Condé, Bd. 4, S. 668f. Vgl. Giulio Alvarotti an Alfonso d'Este, 27. Sept. 1563, Paris, in: ASM, Canc. duc., Amb. Francia 38. Dieser Bericht unterscheidet sich grundlegend von dem der spanischen Gesandten, die, im Gegensatz zu Alvarotti, nicht persönlich in Meulan anwesend waren und denen lediglich der Text der Bittschrift sowie Berichte von Informanten vorlagen. $\mathrm{Zu}$ den Vorgängen in Meulan vgl. auch MUNNS, RICHARDS, Exploiting, S. $210 \mathrm{f}$.

${ }_{48}$ VIENNOT, Transmission, S. 95. Zu den niederlanndischen Statthalterinnen: Barbara WELZEL, Die Macht der Witwen. Zum Selbstverständnis niederlandischer Statthalterinnen, in: Jan HiRSCHBIEGEL, Werner PARAVICINI (Hg.), Das Frauenzimmer. Die Frau bei Hofe in Spätmittelalter und fruher Neuzeit, Stuttgart 2000, S. 287-309. 
nach $^{49}$. Die Macht des Kniefalls lag in der demonstrativen Selbstdemütigung; und nicht anders als Erzherzog Karl fuhlte sich auch der König von Frankreich gezwungen, den Bitten der Knienden nachzugeben, wollte es sich nicht allzu sehr von ihnen distanzieren. Daß ein Kniefall aber nicht nur Unterwerfung und Demultigung signalisierte, sondern konkrete Forderungen unterstrich, gar als Akt des Widerstands gesehen werden konnte, zeigt eine um 1600 in Oberösterreich entstandene Schrift, die als intensivstes Mittel, dem Herrscher eine Bitte vorzutragen, den Kniefall nennt ${ }^{50}$.

Damit der Herrscher den im Rahmen eines Bittgangs vorgetragenen Forderungen größeres Gewicht beizumessen gezwungen wäre, bedurfte es einer großen Anzahl von Teilnehmenden. Entsprechend liefen die Vorbereitungen für den Kniefall in der Kirche von Meulan seit dem Sommer 1563. Karl IX. hatte sich Mitte August in Rouen für volljährig erklären lassen, ein Ereignis, zu dem der gesamte Adel Frankreichs angereist war. Am Tag zuvor hatte ein Treffen der Guise mit ihren Verbündeten stattgefunden, in dessen Verlauf der Bittgang beschlossen und seine Durchführung auf den folgenden Monat festgelegt worden war. Um dem Vorhaben den nötigen Nachdruck zu verleihen, sorgten die Guise für militărische Absicherung und bemühten sich um die Unterstutzung der Großen inner- und außerhalb des Königreichs. Sofort nach dem Treffen zăhlte Anna dem Bruder in einem Brief die Namen derer auf, welche die Aktion unterstützten:

la royne d'Escosse, Messyeur[s] de Lorrayne et Savoye [...], et mesmes Monsieur de Lorrayne y fut venu lui mesmes an personne sans la groysse de Madame sa famme qui est prèste accoucher, lequel an son lieu anvoye Monsieur de Vaudémont pour y assister pour lui, $m$ 'ayant offert ansamble yans [gens] et argant, et [...] tous Mesieur[s] de Bourbon hormis le prinse de Condé y assisteront, et tout les prinses de Franse et presque tous les cappitaynes et signeur[s] de se royaume,

selbst die Königinmutter habe die Begleitung des Bittganges durch einen ihrer Söhne angeboten ${ }^{51}$. Ob die Witwe übertreibt, oder ob die Angelegenheit tatsächlich eine solch breite Unterstultzung genoß, ist unklar. Obwohl die Guise noch Mitte September die Ankunft der Gesandten erwarteten, sagen die Quel-

49 Arno STROHMEYER, Rituelle Kommunikation in vormodernen Herrschaftsordnungen: Kniefalle des oberösterreichischen und steirischen Adels (ca. 1570-1630), in: Zeitenblicke 4 (2005), Nr. 2, unter: www.dipp.zeitenblicke. de/2005/2/Strohmeyer/index_html, Abs. 710, Zitat Abs. 9 (bezüglich der Vorfalle im Erzherzogtum Steiermark 1580-1581). Vgl. den Kniefall vor Rudolf II. in Oberösterreich 1578, in: Ibid. Abs. 12f.

${ }^{50} \mathrm{Zu}$ der Schrift "De resistentia subditorum adversus principem legitima« des Georg Erasmus Tschernembl: STROHMEYER, Rituelle Kommunikation, Abs. 16.

${ }^{51}$ Anna d'Este an Alfonso d'Este, 16. Aug. (1563), Rouen, in: ASM, Canc. duc., Cart. prin. est. 1458/22. Zur militärischen Absicherung der Aktion vgl, das Versprechen von Guy de Daillon, aistre praist [être prêt] a marcher moi et mes assosies et ma compagnie le vint et saitieme de saittembre prochainement venant, 16. Aug. 1563, in: GREENGRASS, Functions and limits, S. 79. 
len nichts über die Teilnahme eines schottischen Agenten oder eines Vertreters Savoyens aus, während Nicolas de Lorraine tatsächlich anwesend war an jenem Sonntag in Meulan. Anna wollte jedoch etwas ganz Konkretes von ihrem Bruder, war sie doch der Meinung, daß sie ihr Vorhaben nicht ohne einen Vertreter ihres eigenen Hauses durchführen könne, und so bat sie den Herzog, ihr als engsten Verwandten den Onkel Don Francesco zu schicken.

Doch Don Francesco kam nicht. Zwar hatte der ferraresische Botschafter die Witwe nach Meulan begleitet, anschließend die Bittschrift der Guise aber nicht unterzeichnen wollen, genausowenig wie der Graf von Vaudémont oder die ebenfalls anwesenden Herren von Nevers und La Roche-sur-Yon. Anna wünschte jedoch die volle Unterstützung Alfonsos, sie wünschte die Solidarität der Familie, wie sie sie von den Guise kannte, vor allem aber wollte sie nicht angewiesen sein auf die Hilfe von $»$ Fremden«, wie sie hinterher dem Bruder schrieb:

Ye n'eusse yames pansé estre si malheureuse que de me voyr abandonnée de vous an ma plus grand nessessité, et qu'il ayt falli que les estrangers $m$ 'ayt aydée et secourrue an un tel fayt, et que vous qui m'estes frèrre $m$ 'ayes ansi delayssée; [...] et un de mes plus grands regres est qu'il ayt fallu que tout le monde ayt connu la manvayse vollonté que portes à votre seur aynée, et qui ne vous fist yames fautte si se n'est de vous avoyr trop aymé.

Nicht nur die Liste der Teilnehmenden und die militärische Absicherung des Unternehmens hatten die Guise im Vorhinein vereinbart, auch die schriftliche Bitte war zuvor von der Königin gelesen und leicht abgeändert worden. Noch Mitte September hieß es aus Paris, die Hinterbliebenen würden nichts unternehmen, bevor sie nicht mit den Herrschern gesprochen und die Erlaubnis für ihren Plan erhalten hätten ${ }^{53}$. Die Kritik an dem zeremoniellen Vorgehen in Meulan ließ daher nicht lange auf sich warten und war in erster Linie aus dem Lager der Gemäßigten zu vernehmen, die den Frieden auf jeden Fall schützen und eine weitere Aufwiegelung des Pariser Volkes verhindern wollten. Als un artifice et un jeu wurde die Aktion bezeichnet, die weniger darauf ausgerichtet gewesen sei, das Mitleid des Königs und des Hofes zu erlangen, als vielmehr par un si triste spectacle die Pariser dazu bewegen sollte, für die Kinder des Ermordeten die gleichen sentimens d'affection et d'attachement zu bewahren wie fur den Vater ${ }^{54}$.

Aller Kritik zum Trotz schien das betont friedvolle Verhalten der Guise, ihr Beharren auf justice, die Bereitschaft, sich dem Spruch von Richtern zu un-

${ }^{52}$ Anna d'Este an Alfonso d'Este, 4. Okt. 1563, Boulogne, in: ASM, Canc. duc., Cart. prin. est. $1568 \mathrm{~A} / 14$.

${ }^{33}$ Giulio Alvarotti an Alfonso d'Este, 10. Sept. 1563, Paris, in: ASM, Canc. duc., Amb. Francia 38.

${ }^{54}$ THOU, Histoire universelle, 1742, Bd. 3, S. 427. Der Autor verlegt den Ort des Geschehens fálschlicherweise nach Paris. 
terwerfen und die Tatsache, daß es die trauernden Frauen waren, die das Anliegen der Familie vortrugen, zunächst von Erfolg gekrönt. Daß die Prinzessin sich jedoch nicht allein auf das durch die Tränen von Witwen und Waisen hervorgerufene Mitleid des Herrschers hatte verlassen wollen, geht aus ihrem Bemühen hervor, die Kulisse ihres Bittgangs mit Vertretern mächtiger in- und ausländischer Fürstenfamilien zu bestücken, um so den nötigen Druck auszuuben. Diese von den Guise verfolgte doppelte Strategie verlangte folglich eine klare Rollenverteilung hinsichtlich der Frage, wer im Rahmen ihres Vorgehens die Stärke zu repräsentieren habe und wer die Schwäche. Und tatsächlich findet sich in einem Brief des ferraresischen Gesandten ein Hinweis auf die Verteilung dieser Aufgaben: Eines Tages fand sich der Konnetabel bei den Guise ein, um ihnen die Nachricht der Königinmutter zu überbringen, daß sie die Waffen niederlegen sollten und daß es Katharinas Wunsch sei, che fosse loro fatto giustitia. Worauf die anwesenden Herren antworteten, che madama [Anna] li risponderia circa la giustitia, e loro circa l'armi ${ }^{55}$.

\section{Paris}

Mit dem königlichen Dekret in der Tasche traten Anna und ihre Begleiter die Reise nach Paris an, um das dortige Parlament mit der Klärung des Mordes zu beauftragen. Doch auch die Châtillon waren nicht untätig geblieben. Obwohl Coligny und seine Brüder in der Bittschrift der Guise nicht explizit genannt worden waren, fürchteten sie die Voreingenommenheit der Pariser Richter. Innerhalb von zwei Tagen entstanden daher verschiedene Schriften, deren Autoren vor dem König und dessen Mutter für die eine oder andere Seite Partei ergriffen. Während der Prinz von Condé gemeinsam mit den Gemäßigten zu demonstrieren suchte, daß eine Übergabe des Falles an das Parlament innerhalb kürzester Zeit den Friedensprozeß zunichte machen würde, welchen Katharina seit Monaten voranzutreiben suchte, forderten die Anhänger der Guise mit Hinweis auf die nachlässige Verfolgung des Mordes, das große Ansehen der Betroffenen, vor allem aber auf das ihnen zustehende Recht: $I l$ est temps que les deux maisons de Lorraine et Ferrare se ressentent de tant d'injustices pour deffendre et maintenir leur droit et hoirs ${ }^{56}$. Der Wille der Königinmutter, den Frieden zu bewahren, behielt die Oberhand. Zwei Tage nach dem Auftritt in der Kirche von Meulan verbot Karl IX. den Pariser Rich-

${ }^{55}$ Giulio Alvarotti an Alfonso d'Este, 23. Nov. 1563, Paris, in: ASM, Canc. duc., Amb. Francia 38.

${ }^{56}$ (Pierre VersorIS?), Discours sur la mort du Duc de Guise, tué devant Orléans, (Ende Sept.) 1563, Kopie des 17. Jh., in: BnF, Fr. 17305, fol. 1-30, hier fol. 17v. Beim Autor könnte es sich um den Advokaten der Guise handeln. Die Darstellung der Gemäßigten findet sich in einer an Katharina von Medici gerichteten Schrift, deren Verfasser wahrscheinlich Michel de L'Hospital ist, o.D. (Ende Sept. 1563), in: Mémoires de Condé, Bd. 4, S. 493f. 
tern, sich des Falles anzunehmen und ubergab die Untersuchungen seinem großen Rat ${ }^{57}$.

Doch Anna und die Ihren gaben sich nicht geschlagen. Am letzten Tag des Monats begaben sich die Guise mit einem Gefolge von etwa zweihundert Mănnern zum Parlament der Hauptstadt. Das Schauspiel, welches sie der Versammlung boten, stand dem Kniefall in Meulan in nichts nach. Von der Sainte-Chapelle aus, wo die Witwe mit ihren Kindern und Angehörigen die Erơffnung der Sitzung erwartet hatte,

ilz ont marché detxx à deux en ordre jusques à la salle du plaidoyé, estant Madame la douayrière [Antoinette de Bourbon] conduite par Monsieur le cardinal de Guyse, et la famme [Anna d'Este] par l'ambassadeur de Ferrare, qui sont tous entrez en ladicte chambre avecques leurs advocatz et conseil [...], et estans entrez se sont séparez les seigneurs an barreau tout debout du cousté des gens d'eglise et les dames devers les gens layz ${ }^{58}$.

Zuvor hatten die Guise noch mehreren Parlamentsmitgliedern Besuche abgestattet, und nun erschienen sie mit einem so großen Gefolge, daß der Saal, obwohl die Sitzung à huy cloz stattfand, voller Menschen war ${ }^{59}$. Die Präsenz der Betroffenen, der Waisen und der Witwe, trug zu der Entscheidung des den Guise von vornherein freundlich gesonnenen Parlaments sicher ebenso bei wie die große Menge ihrer Anhänger. So ist auch hier die Strategie des Zusammenspiels von Schwäche und Stärke auszumachen: Während der Zug von zwei Frauen und einem Geistlichen angefuhrt wurde, drängten sich im Hintergrund zweihundert Männer in den Saal. Ohne die Einwände des königlichen Advokaten zu berlicksichtigen, beschlossen die Parlamentarier die Ernennung von Kommissaren, welche sich uber den Sachverhalt informieren und Beweismaterial sammeln sollten. Damit war der Prozeß gegen den Admiral und seine Verwandten, obwohl ihre Namen nicht gefallen waren, eingeleitet.

Der Sieg der Guise sollte nicht lange wăhren. Mitte Oktober wurde den Mitgliedern des Pariser Parlaments offiziell mitgeteilt, daß der König die Angelegenheit seinem großen Rat ubertragen habe; jede weitere Tătigkeit

${ }^{57}$ Beschluß Karls LX., 28. Sept. 1563; Ratifizierung durch den großen Rat, 2. Okt. 1563, in: BnF, Fr. 6610, fol. $109 f$.

${ }^{88}$ L'Allée de Messieurs de Guise au Parlamant de Paris, 30. Sept. 1563, in: BnF, Fr. 22429, fol. 192r. Vgl. Giulio Alvarotti an Alfonso d'Este, 30. Sept. 1563, Paris, in: ASM, Canc. duc., Amb. Francia 38; Hubert Languet an August von Sachsen, 17. Okt. 1563, Paris, in: LANGUET, Epistolae secretae, S. 266; Pierre BRUSLART, Journal des choses plus remarquables arrivées en France despuis la mort d'Henry second, arrivée le dernier de Juin M.D.LIX. jusques à la Bataille de Montcontour, laquelle fust donnée le 3. ${ }^{\circ}$ Octobre M.D.LXIX., o.O. o.J. [1570], in: Mémoires de Condé, Servant d'Éclaircissement et de Preuves à l'Histoire de M. de Thou, Contenant ce qui s'est passé de plus mémorable en Europe, Bd. 1, London 1743 , S. 1-211, hier S. 136f.

${ }^{59}$ Brief eines unbekannten Informanten an Anne de Montmorency (?), o.D. (29. Sept. 1563), Paris, in: Jules DelaBORDE, Gaspard de Coligny, amiral de France, Bd. 2, Paris 1881, S. 599. 
ihrerseits war fortan untersagt. Obwohl sie in den folgenden Monaten wiederholt von Katharina und Renée beschworen wurde, die Verfolgung Colignys aufzugeben, fand die Prinzessin keine Ruhe, präsentierte dem König unzählige Gesuche und bediente sich aller nur denkbaren Mittel, um »Gerechtigkeit« zu erlangen. Sie sammelte Kopien von wichtigen Dokumenten und Akten, schlug vor, den Fall einem anderen französischen Parlament zu übergeben und erklärte, den Admiral so lange als unschuldig ansehen zu wollen, bis seine Verantwortung fur den Mord in einem Prozeß bewiesen sei $^{60}$. Mit welch nervenaufreibender Ungeduld Anna den Fortgang der Ereignisse verfolgte, geht aus einem Brief ihrer Schwiegermutter hervor: je voy comme l'on vous fait attendre la response de vostre requeste, schrieb Antoinette und gemahnte zur Geduld: ce quy ne se peut promptement faire, se fera avec le tans [...]. Ayes pascience, mamye, et ne vous soucies, tout yra bien à la fin. Und Alvarotti berichtete nach Ferrara, die Prinzessin sei tanto travagliata et sconsolata, ch'ella è degna di gran compassione ${ }^{61}$. Daß der König und seine Mutter dennoch nicht ausschlossen, die Witwe könnte ihren Bemlihungen wieder durch den Auftritt waffentragender Anhänger Nachdruck verleihen, ist schließlich an einem weiteren Friedensgebot Karls zu erkennen, mit welchem er den Parteien noch einmal die gegenseitige gewaltsame Verfolgung verbot und das die Herzogin von Guise wiederum explizit einschlo $\beta^{62}$.

Angesichts der Unmoglichkeit, unvoreingenommene Richter zu finden, die dem Prozeß vorsitzen könnten, beschloß der König Anfang Januar 1564, den Fall sowohl den Parlamenten als auch dem großen Rat zu entziehen, ihn drei Jahre lang ruhen zu lassen und dann persönlich ein Urteil zu fallen. Obwohl Katharina von Medici davon uberzeugt schien, die Angelegenheit zur Zufriedenheit beider Parteien geregelt zu haben, waren die Familie des Ermordeten und ihre Parteigänger alles andere als glücklich: Vraiy est que Mess. ${ }^{r s} D e$ Guyse et tous les Catholicques se monstrent si bas et renduz, comme s'il n'estoit mémoire de la mort de feu Mons.' De Guyse, ny de celle de la Religion. Doch was blieb Anna und ihren Schwägern anderes ubrig, als die Ent-

${ }^{60}$ Giulio Alvarotti an Alfonso d'Este, 15. Okt. u. 3. Dez. 1563, Paris, in: ASM, Canc. duc., Amb. Francia 38; Erklärung Karls LX. zu den Anträgen von Anna d'Este und Gaspard de Coligny, o.D. (März 1564?), in: BnF, Fr. 6610, fol. 28r; Gesuch von Anna d'Este an das Pariser Parlament, 22. Okt. 1563, in: Ibid. fol. 108r.; Auszug aus dem Register des Pariser Parlaments, 3. Dez. 1563, in: Ibid. fol. 128r; Bericht des königlichen huissier Guillaume Robineau, 16. Okt. 1563, in: Ibid. fol. 110v.

${ }^{61}$ Antoinette de Bourbon an Anna d'Este, 15. Nov. (1563), Pont-Saint-Vincent, in: BnF, Fr. 3237, fol. 48r, vgl. PIMODAN, Antoinette de Bourbon, S. 202. Die Stelle bezieht sich auf das von Anna dem Kơnig am 27. Okt. 1563 in Chantilly prăsentierte Gesuch, mit dem sie um die Übertragung des Falles an eines der Parlamente von Toulouse, Bordeaux, Rouen oder Dijon bat, in: BnF, Fr. 6610, fol. 78f. Giulio Alvarotti an Alfonso d'Este, 2. Dez. 1563, Paris, in: ASM, Canc. duc., Amb. Francia 38.

${ }^{62}$ Verbot Karls IX. an die Angehörigen der Hăuser Lothringen und Châtillon, sich gegenseitig zu provozieren oder zu verfolgen, 10. Okt. 1563, in: BnF, Fr. 6610, fol. 104r. 
scheidung zu akzeptieren, vor allem da der König die Prinzessin mit einer großzügigen Schenkung zu überzeugen suchte ${ }^{63}$ ?

In den folgenden zwei Jahren reisten Karl und seine Mutter durch ihr Reich. Die Herzogin von Guise folgte ihnen, nahm an der Taufe des Lothringer Erbprinzen in Bar-le-Duc teil, fuhr nach Avignon und Montpellier, Narbonne und Bordeaux und war in Bayonne bei dem Treffen des Hofes mit der spanischen Königin anwesend. Entfernte Anna sich vom Hof, dauerte es meist nicht lange, bis ihre Freundin sie mittels eindringlicher Briefe zu sich zurückrief anscheinend traute Katharina dem Frieden nicht und zog es vor, die Witwe unter ihrer Kontrolle zu halten ${ }^{64}$. Während der Reise des Königs beschränkten sich die Bemühungen zur Versöhnung der Parteien auf die Ausarbeitung von Heiratsprojekten in unterschiedlichen Konstellationen mit dem Ziel einer Verbindung der Häuser Condé und Guise, die aber unverwirklicht blieben. In diesem Rahmen wurde auch der Plan einer Hochzeit Annas mit Louis de Bourbon gefaßt, den die Witwe jedoch, als Katharina von Medici sie zur Zustimmung überreden wollte, mit den Worten zurückwies, sie würde niemals einen traidor de Dios y de su Rey heiraten, selbst wenn es sich um einen Prinzen von Geblüt handelte ${ }^{65}$. Daneben beweisen weitere Vorfälle, daß der Streit für die Herzogin durch den Erlaß des Königs keineswegs beigelegt war. Als Katharina sie mit der Vermutung konfrontierte, der Kardinal von Lothringen stünde mit ihren Feinden in Friedensverhandlungen, rief Anna, daß er ein noch viel größerer Verräter und ein noch schlechterer Mensch sei als diese, und

${ }^{63}$ Beschluß des königlichen Rates, 5. Jan. 1564, in: Archivo documental Español, Bd. 6, S. 27-29; Katharina von Medici an Marguerite de Valois, Herzogin von Savoyen, Anfang Jan. 1564, in: MÉDICIS, Lettres, Bd. 2, S. 128; Schenkung von Karl IX. der droictz et proffictz [etc.], qui nous sont advenuz et escheuz depuis six ans bis zu einer Höhe von 50000 l.t. an Anna d'Este, 23. Jan. 1564, in: AST (Cast.), Int., PGN, cat. 5, m. 5, n. 8. Das Zitat: Tomás Perrenot de Chantonnay an Philipp II., 12. Jan. 1564, Paris, in: Mémoires de Condé, Bd. 2, S. 188.

${ }^{64}$ Katharina von Medici an Anna d'Este, Ende Febr. 1564, Dez. 1565, in: MÉDICIS, Lettres, Bd. 2, S. 156f., Bd. 10, S. 163; George Carey u. Thomas Smith an Elisabeth I., 27. Juni 1564, Lyon, in: Calendar Elizabeth, 1870, S. 166. Zur Taufe in Bar-le-Duc: La venue à Bar du Roy Charles neuviesme avec le baptesme de mons' le marquis Henry, in: Victor E. GRAHAM, William MCALLISTER JOHNSON, The Royal Tour of France of Charles IX and Catherine de' Medici. Festivals and Entries, 1564-6, Toronto u.a. 1979, S. 186.

${ }^{65}$ Francisco de Alava an Philipp II., 30. Aug. 1564, Valence, in: Archivo documental Español, Bd. 6, S. 374. Vgl. Antoine Perrenot de Granvelle an Georg Sigmund Seld, 9. Jan. 1565, Besançon, in: Papiers d'état du cardinal de GRANVELLE, d'après les manuscrits de la bibliothèque de Besancon, Bd. 8, hg. v. Charles WEISS, Paris 1850, S. 599; Thomas Randolph an William Cecil und Francis Russell, 1. u. 27. März 1565, Edinburgh, in: Calendar Elizabeth, 1870, S. 307, 321; Agrippa d'AUBIGNÉ, Histoire universelle, Bd. 2, hg. v. André THIERRY, Genf 1982, S. 225; THOU, Histoire universelle, 1740, Bd. 3, S. 533. Zu den anderen Eheprojekten: Antoine Sarron an Philipp II., 16. Juni 1564, Lyon, in: Mémoires de Condé, Bd. 2, S. 204: Henri de Bourbon soll Catherine de Lorraine, deren älterer Bruder eine Tochter des Prinzen von Condé heiraten; Charles de Lorraine an Anna d'Este, 18. Aug. 1564, Moyen, in: LORRAINE, Lettres, S. 514: Catherine de Lorraine soll Louis de Bourbon heiraten. 
einen Brief ihrer Mutter, der sie zur Versöhnung mit Coligny aufforderte, zerriß die Witwe vor den Augen des Boten. Auf alle in diese Richtung zielenden Versuche reagierte Anna stets con grandes lágrimas und gran demostración de dolor ${ }^{66}$.

\section{Moulins}

Angesichts der Tatsache, que l'indecision de cest affaire donnoit couleur et pretexte a beaucoup d'inimitiez et divisions qui se nourissoient par my ses sujectz, beschloß Karl IX., die Frist für die endgültige Entscheidung des Falles zu verkürzen. Im Januar 1566 fanden sich daher alle Beteiligten in Moulins ein, nicht ohne daß zuvor strenge Sicherheitsvorkehrungen getroffen worden wären, die es bei Todesstrafe verboten, die Hand an die Waffe zu legen. Die Witwe des Herzogs von Guise gehörte auch hier wieder zu denjenigen, denen die Anwendung von Gewalt zugetraut wurde, wie aus einem Schreiben des Florentiner Gesandten zu ersehen ist, in dem berichtet wird, der Admiral würde von einem Batista da Ferrara, creatura di madama de Guise bedroht. Auch in diesem Fall ist die Frage nach dem Wahrheitsgehalt der Behauptung, schon allein der Unmöglichkeit ihrer Verifizierung wegen, zweitrangig, wichtig ist, daß ein derartiges Gerucht entstand, für glaubhaft gehalten und weitererzählt wurde ${ }^{67}$.

Anna traf in Moulins begleitet von einer Eskorte ein, die der König ihr geschickt hatte ${ }^{68}$. Am 12. Januar, einem Samstag, berief Karl seine Mutter und seine Berater zu sich, um den Ausfuhrungen des Kardinals von Lothringen über den Mord an François und die Verfolgung der Tat zu lauschen. In seiner Rede verwies Charles wiederholt darauf, daß er als Geistlicher und seine Schwägerin als Frau zu einem gewaltlosen Vorgehen gezwungen und folglich auf die Hilfe des Königs und dessen justice angewiesen seien:

Madame ma saur, sa femme, qui est une [sage et] vertueuse Dame et Tutrice legitime de ses enfans, vous supplie, Sire, comme je fais de mon costé, de luy en faire la raison, en quoy elle n'entend se pourvoir, sinon [que] par justice, [...] il vous plaira penser, Sire, que je suis un Prestre et Madame ma saur une femme, qui ne pouvons ny ne voulons jamais des-obeïr à vos commandemens 69 .

${ }^{66}$ Francisco de Alava an Philipp II., 27. Dez. 1564, 2. Apr. u. 5. Mai 1565, in: Archivo documental Español, Bd. 6, S. 562, Bd. 7, S. 218, 310.

${ }^{67}$ Bescheid der Unschuld Colignys, 29. Jan. 1566, Moulins, in: Archivo documental Español, Bd. 8, S. 214f.; Anweisung Karls IX. zur Sicherheit in Moulins, 7. Jan. 1566, in: DELABORDE, Gaspard de Coligny, Bd. 2, S. 604; Gianmaria Petrucci an Cosimo und Francesco de' Medici, 21. Jan. 1566, in: DESJARDINS (Hg.), Négotiations diplomatiques, Bd. 3, S. 523.

${ }^{68} \mathrm{Karl}$ LX. an Anna d'Este, 8. Jan. 1566, Moulins, in: BnF, Fr. 3213, fol. 1r.

${ }^{69}$ Rede von Charles de Lorraine, 12. Jan. 1566, in: Du BouCHET, Preuves de l'Histoire, S. 540f. Die Wörter in Klammern wurden von mir anhand BnF, Fr. 3951, fol. 98r ergänzt. 
Der Konig beeilte sich daraufhin zu versichern, die Angelegenheit par voye juste et equitable regeln zu wollen, worauf die Witwe und ihr Schwager erklärten, die équitable raison et justice qu'ilz ont tousjours attendus et espérés de sa bonté et clemence entgegenzunehmen. Da das Urteil jedoch noch einmal verschoben wurde, genugten Karl die einfachen Zusicherungen der Prinzessin und ihrer Angehörigen nicht. Die Beteiligten mußten schwören, bis zur endgültigen Klärung des Falles weder direkt noch indirekt, durch Taten oder durch Worte etwas gegeneinander zu unternehmen ${ }^{70}$.

Nach all diesem Hin und Her, nach Jahren des Wartens und der Ungeduld, in denen Katharina und ihr Sohn mit Gesuchen und Bitten regelrecht überhäuft worden waren, würde man bei der Verkündung des endgültigen Urteils eine gewisse feierliche Stimmung oder einen besonderen zeremoniellen Rahmen erwarten. Die Sitzung des königlichen Rates am 29. Januar 1566 verlief jedoch prosaisch. Nachdem die Beweisstücke verlesen worden waren und Coligny geschworen hatte, den Mord weder befohlen noch gutgeheißen zu haben, erklärte ihn der König für purgé, [deschargé] et innocent und befahl allen Beteiligten silence perpetuel ${ }^{71}$. Der Fall war entschieden, der Admiral für unschuldig erklärt. Sollten sich Katharina und ihr Sohn in den folgenden Monaten auch zu ihrem Werk beglückwünschen, von dem sich Karl ung merveilleux repoz pour mon royaume et mes subgectz erhoffte, so zeigen verschiedene Zwischenfälle, daß durch das Urteil und die ihm folgende offizielle Versöhnung aus den ehemaligen Feinden keineswegs Freunde geworden waren ${ }^{72}$. Schon wenige Wochen nach dem Friedensschluß vom Januar 1566 wurde dem spanischen Botschafter versichert, die Häuser Guise und Châtillon würden niemals Freunde sein, und noch Jahre später hatte der König dagegen vorzugehen, que ceulx de Guyse et de Chastillon faisoient chascun de leur part quelzques amas et assemblées de gentilzhommes les ungs à l'encontre des autres $^{73}$.

Eine Aufgabe nur, die vielleicht schwierigste des gesamten Prozesses, blieb Karl und seiner Mutter nach der Urteilsverkündung noch zu erledigen: die Überzeugung der Witwe. Die beiden hătten sie in ein Zimmer gesperrt, erzăhl-

${ }^{70}$ Schriftliches Versprechen mit den Originalunterschriften von Charles de Lorraine und Anna d'Este, 12. Jan. 1566, in: BnF, Fr. 6610, fol. 135r. Die Zitate aus dem Gebot Karls IX., bis zur Klärung des Falles nichts gegeneinander zu unternehmen, 12. Jan. 1566, in: BnF, Fr. 6610, fol. 139 f.

${ }^{71}$ Bescheid der Unschuld Colignys, 29. Jan. 1566, Moulins, in: Archivo documental Espanol, Bd. 8, S. 214-218, Zitate S. 217. Das Wort in Klammern wurde von mir anhand BnF, Fr. 6610, fol. 158r korrigiert.

${ }^{72}$ Karl IX. an Arnaud du Ferrier, 27. Jan. 1566, Moulins, in: BnF, Fr. 10735, fol. 128v.

${ }^{73}$ Francisco de Alava an Philipp II., 16. März 1566, Moulins, in: Archivo documental Español, Bd. 8, S. 269; Karl IX. an Arnaud du Ferrier, 26. Dez. 1571, Amboise, in: CHARLES IX, Lettres à M. de Fourquevaux, Ambassadeur en Espagne, 1565-1572, hg. v. Célestin DOUAIS, Montpellier 1897, S. 373f. 
te Anna spăter dem spanischen Botschafter, um sie zu überzeugen, daß die Versöhnung der Häuser Guise und Châtillon auf jeden Fall vollzogen werden müsse, doch sie habe nur geweint und gebeten, nicht weiter uber die Angelegenheit sprechen zu müssen. Katharina erreichte lediglich eine allgemeine Unterwerfung ihrer Freundin unter den königlichen Willen und eine Zusage zur Versöhnung mit den Châtillon, nicht jedoch eine Absage an la venganza que requeria tan gran maldad. Für den spanischen Gesandten war Anna la mujer del mundo más desconsolada, doch verbarg sich hinter der offensichtlichen Schwäche der Prinzessin eine Stärke und Bestimmtheit, gegen die selbst die Königinmutter nichts auszurichten vermochte ${ }^{74}$. Daneben bestätigt ein früherer Vorfall die Vermutung, die Witwe habe Tränen und Kniefallle auch in kleinem Rahmen dazu genutzt, sich nie einem fremden Willen beugen zu müssen. Als ihr Katharina an einem Tag Ende November 1563 erklärte, die Feinde miteinander versöhnen zu wollen, befanden sich außer Renée de France noch die Brilder Châtillon im Raum:

[Anna] si buttò in ginocchio d'avanti la Maestà Sua, piangendo et supplicandola che non la volesse astringere à questo, dicendo, che Lei non perdonerà mai a chi era stato causa di tanto tradimento, et che la Maesta Sua ne dovesse far giustitia, si come più volte le haveva promesso, et non ci mettesse più tempo in mezzo acciò dalla dilatione, che si faceva, non ne cavasse la morte sua et de' suoi figliuoli, com' era stata quella di suo Marito; et con questo si licentio ${ }^{75}$.

Coligny und seine Bruder hatten dem Schauspiel beigewohnt, ohne ein Wort zu sprechen. Madama di Ferrara volle essortare la figliuola á far pace, et non pensar più a tal cosa, et cercare di quietare l'animo suo, berichtet der Beobachter weiter, doch erfolglos: la figliuola non dette altra risposta alla madre. Auch hier wieder Tränen, ein Kniefall und die Anspielung auf ihren Tod und den ihrer Kinder, doch am Ende unterwarf die Prinzessin sich nicht.

Was hatte Anna aus den jahrelangen Prozessen gewonnen, die sie in erster Linie viel Geld gekostet hatten? Denn jeder juristische Vorgang, jede Urkunde und jede Kopie wurde zu ihren Lasten abgerechnet. Hinzu kamen die Spesen ihrer Advokaten für Reisen und für die Eingaben beim König sowie die Entlohnung ihres Vertreters im Pariser Parlament ${ }^{76}$. Letztendlich war der Nutzen

\footnotetext{
${ }^{74}$ Francisco de Alava an Philipp II., 3. Febr. 1566, Moulins, in: Archivo documental Español, Bd. 8, S. 221.

${ }^{75}$ Mandosio an Mons. Tolomeo, 6. Dez. 1563, Paris, in: FonTANA, Renata di Francia, Bd. 3, S. $96 f$.

${ }^{76}$ Bartholomé Fayé, Louis Gayant, Mitglieder des Pariser Parlaments, Procès-verbal, 26. Okt. 1563, in: BnF, Fr. 6610, fol. 108-111, hier fol. 108r; Rechnungsbuch 1563, fol. 82v, 99r. Allein die Spesen der Advokaten Versoris und Saint-Méloir betrugen in jenem Jahr 125 l.t., zusätzlich standen alle Juristen auch noch auf der ordentlichen Lohnliste des neuen Herzogs von Guise, in: BnF, Clair. 816, S. 188. Das folgende Zitat: Rede von Charles de Lorraine vor dem königlichen Rat, 12. Jan. 1566, in: BnF, Fr. 3951, fol. 99r.
} 
dieser Prozesse aber größer als die Kosten. Die Herzogin hatte für Ehre und Ansehen ihrer Familie gekämpft und sich dafur eingesetzt, [de] reparer l'honneur de ceux qui sont offensez. Ihre Bemühungen um die Ehre des Hauses hatten nicht zuletzt ihrer eigenen Reputation gedient, denn Annas unbeugsame Haltung war ein Beweis für die Treue, welche sie ihrem Gemahl auch nach dessen Tod entgegenbrachte. Sie, die fur das Andenken des Ermordeten alles in ihrer Macht Stehende getan hatte, genoß einen mehr als tadellosen Ruf, und nun war es ihr möglich, eine zweite Eheverbindung einzugehen. Im Mai 1566 sollte sie Jacques de Savoie, Herzog von Nemours, heiraten.

\section{Die Bartholomäusnacht als späte Rache der Witwe?}

Die Frage, welche Rolle Anna beim Mord an Coligny und in der Bartholomäusnacht gespielt haben mag und ob die Ereignisse als Nachspiel zu den Auseinandersetzungen der vorangegangenen Jahre betrachtet werden müssen, ist überaus schwierig zu beantworten. Zeitgenössische wie moderne Autoren vertreten nicht selten radikale Positionen, denen gemäß sie die Mordnacht entweder mitentschieden habe oder, gemeinsam mit ihrer Familie, nur Werkzeug der Königinmutter gewesen sei. Die These der Vendetta, derzufolge sie mit dem Attentat auf Coligny den Mord an ihrem Gemahl rächen wollte, findet sich häufig, bietet sie doch eine einfache Erklärung des Geschehens. Daß der König erneute Vorfälle zwischen den Guise und den Châtillon tatsächlich bereits in der ersten Hälfte des Jahres 1572 befürchtete, wird an seiner Bestätigung des Urteils von Moulins im März sowie an Colignys erneuter Unschuldsbeteuerung im Mai deutlich. Doch bestand für den Admiral ausgerechnet von Seiten der Herzogin von Nemours Gefahr? ${ }^{77}$

${ }^{77}$ Nicola M. SUTHERLAND, The Massacre of St Bartholomew and the European Conflict, 1559-1572, London, Basingstoke 1973, S. 227; BouILLÉ, Histoire, Bd. 2, S. 494. Zu Annas undurchsichtiger Rolle: GARRISSON, Saint-Barthélemy, S. 67: „Au milieu des hommes, surgit dans l'entourage de Catherine une étrange figure, Mme de Nemours«; LAMBIN, Femmes de paix, S. 159: »L'ambivalence d'Anne d'Este est partout décelable [...] et ses motivations exactes demeurent mystérieuses«; Gabriel BRIZARD, Du massacre de la SaintBarthélemi, et De l'influence des Etrangers en France durant la Ligue, Bd. 2, Paris 1790, S. 74f.: "sa réputation de vertu ne la rendit que plus dangereuse«. Zur Vendetta-These im "Discours du Roy Henry troisiesme [...] des causes et motifs de la St. Berthelemy» von 1623: Denis CROUZET, La nuit de la Saint-Barthélemy. Un rêve perdu de la Renaissance, Paris 1994, S. 106f., 313, 467. Laut GARRISSON, Saint-Barthélemy, S. 84, habe Katharina während einer Unterredung mit Anna den Guise die Vendetta gegen Coligny erlaubt. Henry HELLER, Anti-Italianism in Sixteenth-Century France, Toronto u.a. 2003, S. 110, behauptet gar, die Königinmutter habe die Herzogin von Nemours mit der Suche nach einem Mörder für Coligny beauftragt. Vgl. auch Jean-Louis BOURGEON, L'assassinat de Coligny, Genf 1992, S. 41 f.; Marc VENARD, Arrêtez le massacre!, in: Revue d'histoire moderne et contemporaine 39 (1992) S. 645-661, hier S. 650. 
Die Sommermonate des Jahres 1572 waren für Anna keine leichte Zeit. Im Frühjahr hatte sie die Mutter in Montargis besucht und war dann nach Paris gereist, wo sie ihre Prozesse vorantreiben wollte. Jacques de Savoie hielt sich in Piemont auf, erst Ende August sollte er sich in Richtung Frankreich auf den Weg machen. Die Prinzessin war vierzig Jahre alt und schwanger, im August bereits im siebten Monat, und sie hatte einen Unfall mit ihrer Kutsche gehabt, war gestürzt. Als Anna in Paris ankam, fand sie die Königinmutter krank, sie konnte sich also nicht ihren Angelegenheiten widmen, sondern blieb bei der Freundin, non pas sans travail, wie Renée dem Schwiegersohn mitteilte. Als Katharina genesen war und die Herzogin in ihr Hôtel de Nemours umzog, erfuhr sie von der Krankheit ihrer kleinen Tochter, die Ende Juni starb. AuBerdem erhielt sie in regelmäßigen Abständen Briefe von ihrem Gemahl, der unter schwerer Gicht litt und oft vor Schmerzen die Feder zu halten nicht in der Lage war. Die Trennung von Jacques belastete die Prinzessin sehr, und Ende Juni unterrichtete Renée ihn über den besorgniserregenden Zustand ihrer Tochter:

[Anna] estoit bien ennuyee de vous avoir laisse et lasse du chemin et da le doubte de Groise et de noz affaires a quoy elle a travaille beaucoup [...] elle a besoing de repos et de navoyr poinct dennuy Car elle en a eu tant et tant de traverses en ceste groisse depuis la cheute de son coche leslongnement de vostre presence que luy est si difficile et grief a porter aussi le trovail quelle a prins en la maladye de la royne mere Et puis la derniere nouvelle de nostre dicte petite fille et de noz affaires qui ont avec elle besoing de vostre presence ${ }^{78}$.

In den folgenden Wochen schien sich die Prinzessin etwas erholt zu haben, sie arbeitete nun viel mit Katharina von Medici, manchmal bis spät in die Nacht. Die Hochzeit des Königs von Navarra galt es vorzubereiten, Vortrittsstreitigkeiten zwischen der Herzogin von Nemours und der von Longueville zu klären, die vielen Gäste unterzubringen. Renée und Henri, Annas ältester Sohn, kamen in die Hauptstadt, und die Dame von Montargis wohnte bei ihrer Tochter im Hôtel de Nemours. Ihr eigenes Gefolge brachte Anna im Haus eines ehemaligen Lehrers ihres Sohnes unter, welches ihr von den Leuten des Königs zu diesem Zwecke zugewiesen worden war. Die Prinzessin selbst schlief zunächst im Louvre, doch, wie der Nuntius am 22. August berichtete, per esser gravida e alquanto indisposta, si partì alcuni giorni sono. Anna kehrte also in ihr Hôtel zurück, ihre Mutter wich in eine andere Unterkunft aus ${ }^{79}$.

78 Renée de France an Jacques de Savoie, 26. Juni 1572, Montargis, in: MÜNCH (Hg.),
Denkwürdigkeiten, S. 198f.
${ }^{79}$ Antonio Maria Salviati an Filippo Boncompagni und Tolomeo Galli, 21. Juli u. 22. Aug.
1572, Paris, in: Correspondance du nonce en France Antonio Maria Salviati (1572-1578),
Bd. 1, hg. v. Pierre HURTUBISE, Robert TOUPIN, Rom 1975, S. 164, 197; Gianmaria Petrucci
an Francesco de' Medici, 23. Juli 1572, in: DESJARDINS (Hg.), Négotiations diplomatiques,
Bd. 3, S. 799. SUTHERLAND, Massacre, S. 322, folgert fâlschlicherweise, Anna habe Paris
verlassen und sei zum Zeitpunkt der Bartholomausnacht nicht in der Stadt gewesen: „It 
Der Schuß, welcher am Vormittag des 22. August die Brust Colignys nur zufällig verfehlte, war von einem Fenster eben desjenigen Hauses abgefeuert worden, in dem das Gefolge der Herzogin von Nemours logierte. Die allgemeine Meinung lautete daher, Anna müsse von dem Attentat zumindest gewußt haben; die Mörder, so erzählte man sich, sono della casa di Madama de Nemours, la quale il mondo vuole sappia tutto. Einige Tage später hieß es: Altri giudicavano che Madama de Nemours avesse procurato il copo, wobei die Beobachter in dieser Ansicht bestärkt wurden durch die Tatsache, daß es sich bei den einzigen Mitgliedern des Hofes, die dem verletzten Admiral keinen Besuch abstatteten, um den Herzog von Guise, seine Gemahlin und deren Schwester sowie - die Herzogin von Nemours handelte ${ }^{80}$. In den folgenden Tagen und Wochen scheint sich die Ansicht verfestigt zu haben, Katharina von Medici sei die Auftraggeberin des Anschlags gewesen, ohne Wissen des Königs, aber mit Beteiligung ihrer Freundin. Die wildesten Gerulchte begannen in Paris zu kursieren und wurden von den ausländischen Gesandten an den Höfen Europas verbreitet. Das Haus, von dessen Fenster aus der Schuß abgegeben worden war, wurde kurzerhand zur Wohnstätte der Prinzessin erklärt, welche sich an einen anderen Ort zurlickgezogen und ihre Gemächer leerstehen gelassen habe, um den Attentätern leichtes Spiel zu ermöglichen. Oder: Annas Almosenpfleger sei es gewesen, der den Mörder mit Wissen seiner Herrin in besagtem Gebäude untergebracht habe. Oder: Henri habe seiner Mutter vorgeschlagen, sie selbst solle auf den Admiral schießen, während dieser sich bei der Königinmutter aufhalte, persuadendola con il mostrarli quanto fusse facil cosa di scaricar un archibuso, ad uno che non si guarda, et che essendo tra donne, et con la Regente ragionevolmente doveva disporre ogni sospetto ${ }^{81}$. Vom Vorwurf der Mitwisserschaft bis hin zu der Behauptung, die Prinzessin hätte selbst Hand an die Mordwaffe legen können, finden sich alle Vorstellungen in diesen Berichten. Welchen Teil Anna tatsăchlich zu dem Anschlag beigetragen hat, ist unmöglich zu bestimmen, und so kann es bei der Beurteilung der Quellen auch nicht um die Beantwortung dieser Frage gehen. Interessant ist vielmehr, was der Herzogin zugetraut wurde, wie groß man ihren $\mathrm{Haß}$ auf den Admiral einschätzte und vor allem, wie viele unterschiedli-

would be interesting to know where madame de Nemours may have been «. Doch Anna befand sich die ganze Zeit über in Paris, erst im Louvre, dann im Hôtel de Nemours.

${ }^{80}$ Gianmaria Petrucci an Francesco de' Medici, 23. Aug. 1572, in: DESJARDINS (Hg.), Négotiations diplomatiques, Bd. 3, S. 808; Filippo Cavriani an Bartolomeo Concini, 27. Aug. 1572, in: Ibid. S. 813.

81 Bericht des außerordentlichen Gesandten Giovanni Michiel an die Serenissima, 11. Nov. 1572, in: FIRPO (Hg.), Relazioni di ambasciatori, S. 655; Contre le Massacre de la Sainct Barthélemy, 15. Nov. 1572, in: BnF, Fr. 17309, fol. 56-65, hier fol. 58r; Antonio Maria Salviati an Tolomeo Galli, 22. Sept. 1572, Paris, in: Correspondance Salviati, Bd. 1, S. 165. Das Zitat aus dem Brief vom 2. Sept., in: Ibid. S. 133f. 
che Blickwinkel es auf sie und ihre Rolle während der Ereignisse im Sommer 1572 gibt.

Nicht weniger ambivalent sind die Meinungen der Beobachter hinsichtlich Annas Anteil an der Entscheidung zur Ermordung der Hugenotten. Zwar wird die Prinzessin mit einigen geheimen Unterredungen in Verbindung gebracht, die eine zwischen ihr selbst und der Königinmutter, die andere zwischen den Herzögen von Guise und von Aumale en la chambre de madame de Nemours, doch wird ihr Name nicht in einem Zuge mit denjenigen genannt, die das Morden beschlossen haben sollen. Tatsächlich stimmt die Forschung heute darin überein, daß die Entscheidung vom König und seinem Rat getroffen worden sein $\mathrm{mu}^{82}$. Die Zeitgenossen jedenfalls scheinen der Meinung gewesen zu sein, daß sich die Rachelust der Herzogin allein auf die Person des Admirals beschränkt habe und sie in die weiteren Morde jener Tage und Nächte nicht verwickelt gewesen sei. Doch im Herbst 1572 wurde von den Hugenotten ein Brief des Herzogs von Guise abgefangen, in dem dieser seiner Mutter die Entscheidung Karls IX. mitteilte, d'exterminer totalement et raser tout le reste de ceste vermine seditieuse, Anna also zumindest $\mathrm{zu}$ einem späteren Zeitpunkt von diesbezüglichen Plănen des Königs wußte ${ }^{83}$.

Selbst hinsichtlich der Frage, ob die Herzogin von Nemours während der Bartholomäusnacht verfolgten Personen eher geholfen oder sie verraten habe, besteht Unklarheit. Jules Gassot, ein Augenzeuge der Vorfälle und den Guise wohigesonnen, die er offensichtlich zu entlasten suchte, berichtet, Anna habe gemeinsam mit ihrer Familie mehrere Menschen vor der fureur et violence du peuple gerettet, eine Darstellung, die von Arnaud d'Ossat bestätigt wird ${ }^{84}$. Sicher ist, daß die Herzogin, wohl auf Betreiben der Mutter, das Toulouser Parlamentsmitglied Arnaud de Cavagnes vor seinen Verfolgern versteckte. Unsicher ist, ob dieser dann zufallig aufgespürt wurde oder ob Anna ihn, wie man in Paris munkelte, an die Leute des Königs ausgeliefert hatte ${ }^{85}$. Auf jeden Fall aber rettete die Prinzessin der Tochter von Michel de L'Hospital, ihrem ehemaligen Kurator, das Leben. Aus dessen Dankesschreiben ist zu erfahren, daß Anna die neunfache Mutter mit großem Mut vor dem aufgebrachten Mob

\footnotetext{
${ }^{82}$ Desseing de ceulx qui soubz le nom et auctorité de Sa majesté ont faict le massacre advenu ce 24. jour d'aoust 1572, 15. Nov. 1572, in: BouRGEON, L'assassinat de Coligny, S. 94, Anm. 10; Antonio Maria Salviati an Tolomeo Galli, 2. Sept. 1572, Paris, in: Correspondance Salviati, Bd. 1, S. 133f.; THOU, Histoire universelle, 1740, Bd. 4, S. 576. Zum Hintergrund der Ereignisse in Paris: Barbara B. DIEFENDORF, Prologue to a Massacre: Popular Unrest in Paris, 1557-1572, in: American Historical Review 90 (1985) S. 1067-1091.

${ }^{83}$ Henri de Lorraine an Anna d'Este, 27. Okt. 1572, Paris, in: Mémoires de l'Estat de France, sous Charles Neufiesme. Contenant les choses plus notables, faites et publiées tant par les Catholiques que par ceux de la Religion, Bd. 1, »Meidelbourg « 1577, S. 769.

${ }^{84}$ GASSOT, Sommaire mémorial, S. 109; LANGLOIS, Les hôtels, S. 42, Anm. 1.

${ }^{85}$ Gianmaria Petrucci und Antonio Maria Salviati an Francesco de' Medici, 8. Sept. 1572, in: DESJARDINS (Hg.), Négotiations diplomatiques, Bd. 3, S. 837. Vgl. Christiane GIL, Renée de France. »Ce lys au milieu des épines«, Paris 1990, S. 233-235.
} 
beschützt und sie dann in einer verhangenen Sänfte, von der die Leute annahmen, sie gehöre zum Gefolge der Renée de France, aus der Stadt und in Sicherheit gebracht habe. Quis Deus hunc animum tibi, virgo, quis hanc tibi mentem / Spiritus immisit? fragt sich L'Hospital und meint, in ihr eine wahre Nachkommin des großen Ludwig XII. zu erkennen ${ }^{86}$.

Ihre Mutter galt es für die Prinzessin auf jeden Fall zu retten. Am Abend des 24. August hatten sich die beiden Damen zusammen mit Renées Gefolge und einer Menge Wachen an einen sicheren Ort zurückgezogen. Vier Tage später, noch bevor das Morden in Paris aufgehört hatte, verließ Renée die Stadt in Richtung Montargis, beschützt von einer Truppe Männer des Herzogs von Guise. A Montargis, ordinaria residenza di Madama di Ferrara, non si predica più alla ugonotta, lauteten die Neuigkeiten nach ihrer Ankunft dort, et poi ha licentiato tutti li ministri, et molti della sua famiglia che vivevano alla ugonotta si sono ridotti alla vera relligione catolica ${ }^{87}$. Zwar befand sich die Mutter in Sicherheit, doch Anna war dennoch in Sorge um sie, wie aus einem ihrer Briefe zu erfahren ist, und sie sorgte sich um den Gemahl, welcher in jenen unruhigen Zeiten auf dem Weg nach Paris war:

Nayant encores eu aulcunes de voz nouvelles depuis vostre arrivee a Montargis je vous ay voulu envoyer ce laquais par lequel je vous supplie treshumblement men vouloir mander et faire part de vostre disposition. Aussi si avez entendu quelque chose de . $^{r}$ mon mary parceque [...] Je nay eu aulcune seurte sil continuera son veoiaige ou bien sil aura differe ayant entendu ce qui sest passe [...]. Icy semble que les choses soient fort paisibles et ne sy est faict ny continue aulcun meurdre ny deplaisir a personne qu'on ait entendu.

Die Frage, ob der Mord an Coligny und die Bartholomäusnacht mit dem Anschlag auf den Herzog von Guise rund zehn Jahre vorher in Zusammenhang steht, ist letztlich nicht zu beantworten. Nach dem Tod des Herzogs soll dessen Witwe, so zumindest erinnert sich Brantôme, dem ältesten Sohn jeden Morgen das blutbeschmierte Hemd seines Vaters vor die Nase gehalten haben mit dem Worten: Advise-la bien, et souviens-toy bien, quand tu seras grand, de vanger cecy: autrement je te desherite ${ }^{89}$. Sicher ist diese Geschichte ebenso dem Reich der Legenden zuzuweisen wie die Behauptung, Henri habe seiner Mutter die Exekution des Admirals durch ihre eigene Hand angetragen. Sicher ist aber auch, daß Anna mit ihren unablässigen Eingaben bei den Gerichten

\footnotetext{
${ }^{86}$ Michel de L'Hospital an Anna d'Este, 1572, in: L'HospITAL, Euvres complètes, S. 491494, Zitat S. 492. LAMBIN, Femmes de paix, S. 165, nennt darüber hinaus den Namen des Pastors Pierre Merlin, der von Anna gerettet worden sei.

${ }^{87}$ Giovan Battista Salvato an Guglielmo Gonzaga, 13. Sept. 1572, Paris, in: ASMan, AG 656; Gaspare Fogliani an Alfonso d'Este, 24. Aug. 1572, Paris, in: FonTANA, Renata di Francia, Bd. 3, S. $276 f$.

${ }^{88}$ Anna d'Este an Renée de France, 2. Sept. 1572, Paris, in: MüNCH (Hg.), Denkwürdigkeiten, S. 205.

${ }^{89}$ BRANTÓME, Recueil des Dames, S. 708.
} 
und beim König sowie mit bedeutungsvollen Aktionen vor dem Parlament und in einer Kirche, im Rahmen derer der Name Colignys zwar selten genannt, immer aber gehört wurde, einen Teil zu dem Klima beigetragen hat, das schließlich die Ereignisse vom Sommer 1572 ermöglichte.

3. »Paines, labeurs, fraitz et continuelles poursuittes«

Einige weitere Prozesse

Die Verfolgung der für den Mord an ihrem Gemahl Verantwortlichen war für Anna nur der Auftakt zu einer ganzen Reihe von Prozessen, derentwegen sie sich in den folgenden Jahrzehnten vor die königlichen Gerichte begab. Den bedeutendsten davon, in dessen Verlauf grundlegende Fragen geklärt werden mußten, die nicht zuletzt auch den territorialen Bestand der französischen Krone betrafen, stand sie gemeinsam mit der Mutter durch. Überhaupt setzte sich die Prinzessin während der fünfzehn Jahre, die Renée nach dem Tod ihres Gemahls in Frankreich verbrachte, oft vor dem König für deren Anliegen ein und vermittelte in schwierigen Situationen.

\section{Das innige Verhältnis von Mutter und Tochter}

Anfang September 1560 hatte Renée mit einem rund dreihundert Personen zählendem Gefolge Italien verlassen und wurde sechs Wochen später von ihrer Tochter sowie dem gesamten Hof in Orléans willkommen geheißen. Einer der Gründe für die Rückkehr der Witwe nach Frankreich war, a modo suo leben zu wollen, was bedeutete, daß sie in ihrer Residenz in Montargis reformierte Prediger hörte und verfolgten Hugenotten Asyl gewährte ${ }^{90}$. Doch kaum zwei Jahre später, als das Königreich kurz vor dem Ausbruch des ersten Religionskrieges stand, wollte Karl IX. derart abweichendes Verhalten nicht länger tolerieren. Zwar war seit dem Edikt vom Januar 1562 die Ausübung des reformierten Kultes außerhalb der Stadtmauern oder aber im privaten Kreise erlaubt, doch wagten es die Hugenotten von Montargis, ihre Predigten in der Hauptkirche der Stadt zu halten. Der König und seine Mutter, die unter groBem Druck seitens der radikalen Katholiken standen, wußten sich nicht anders zu helfen, als Renée die Ausübung der reformierten Religion zu verbieten. Mit der Überbringung des Befehls wurde die Tochter der rebellischen Fürstin

${ }^{90}$ Carlo OLIVI, Annali della città di Ferrara dalla sua prima origine fine al dominio delli ultimi duchi estensi, 1790, in: BA, cl. I, 105, Bd. 1, S. 739 (2. Sept. 1560). Vgl. Anna d'Este an Alfonso d'Este, 9. Nov. (1560), Orléans, in: ASM, Canc. duc., Cart. prin. est. 1568 A/14. 
beauftragt, die einzige, der Katharina die Ausfuhrung dieses delikaten Auftrags zuzutrauen schien. So begab sich Anna nach Montargis, um der Mutter im Namen des Königs zu befehlen, che ella mandi via li minstri, et viva Catholicamente ò se ne vada; et non lo volendo fare [che] sarà posta in pregione ${ }^{91}$.

Während des zweiten Religionskrieges fungierte Anna wieder als Vermittlerin zwischen ihrer Mutter und dem Hof. Karl IX. wollte Truppen in Montargis stationieren, woraufhin Renée, die sich vorstellen konnte, was es bedeutete, katholische Soldaten in ihrer Stadt zu haben, die Sicherung des Ortes aus eigener Kraft versprach. Die Tochter bat sie um Fursprache vor Katharina und ihrem Sohn, die Anna daraufhin zu überzeugen suchte, que Madame ma mère est femme de promesse. Die Prinzessin hatte Erfolg und konnte kurz darauf der Mutter mitteilen, daß ihr die Garnison erspart bliebe ${ }^{92}$. Auch in den Kriegen der folgenden Jahre setzte Anna sich für Renée ein, versuchte die Vertreibung der Hugenotten aus ihrer Residenz zu verhindern, bemühte sich um Papiere pour seus de Montargis und unterstützte sie, gemeinsam mit ihrem Gemahl, so gut es ging ${ }^{93}$. Erst nach den Morden der Bartholomäusnacht verringerten sich die Möglichkeiten für ein Einschreiten zugunsten der Königstochter und ihrer hugenottenfreundlichen Politik. Im Herbst 1572 präsentierte der Herzog von Nemours Katharina einige Briefe seiner Schwiegermutter, in denen sie bat, in ihrem Schloß in Montargis die Predigt hören zu dürfen, worauf die Königin antwortete, daß ihr Sohn weder seinen Brudern noch ihr selbst jemals erlauben würde, eine andere Religion als die seine auszuuben, womit sie ihm jedes weitere Wort in dieser Angelegenheit untersagte ${ }^{94}$. Derweil sorgte Anna sich um die zum Haushalt ihrer rebellischen Mutter gehörenden Personen, wăhrend sie sich um ihr eigenes Ansehen bei Hofe nicht zu kümmern schien: $J$ 'ai crainte pour vos serviteurs et aussi que si l'on sait qu'avez quelque ministre avec vous que l'on ne leur fasse peine. [Ye] vous supplie très humblement

${ }^{91}$ Alessandro Fiaschi und Giulio Alvarotti an Alfonso d'Este, 1. Apr. 1562, Paris, in: FoNTANA, Renata di Francia, Bd. 3, S. 69. Das Wort in Klammern wurde von mir anhand ASM, Canc. duc., Amb. Francia 50 ergänzt. Erst im Herbst konnte eine endgulltige Einigung erzielt werden: Katharina von Medici an Anna d'Este, o.D. (16. Sept. 1562), in: MÉDICIS, Lettres, Bd. 1, S. 617.

${ }^{92}$ Bouchefort an Renée de France, 25. Febr. 1568, Paris, in: MÉdicis, Lettres, Bd. 3, S. 128; Anna d'Este an dies., o.D. (Febr. 1568), in: Gabriel BraUN, Position de Renée de France durant la Seconde Guerre de Religion, in: Bulletin de la Société de l'histoire du protestantisme français 145 (1999) S. 661-684, hier S. 673.

${ }^{93}$ Gaspare Fogliani an Alfonso d'Este, 24. Sept. 1569, in: FONTANA, Renata di Francia, Bd. 3, S. 202; Anna d'Este an Renée de France, o.D. (Anfang Nov. 1568), in: BnF, Fr. 3230, fol. 10r. Das Zitat aus dem Brief o.D. (1570?), in: MÔNCH (Hg.), Denkwürdigkeiten, S. 285.

${ }^{94}$ Anna d'Este an Renée de France, o.D. (Herbst 1572), in: BnF, Fr. 3230, fol. 2r u. POIZAT, Princesse de Clèves, S. 111. 
voulloir panser, de ma part j'y panserai come aussi fera monsieur mon mari pour vous servir ${ }^{95}$.

Anna und Renée waren sich stets eng verbunden. Das große Vertrauen zwischen Mutter und Tochter und die gegenseitige Achtung kann aus Briefen und Gesten ersehen werden, aber auch aus Berichten über verschiedene Vorkommnisse. Schon vor ihrer Rückkehr nach Frankreich hatte die Herzogin von Ferrara ihrer Tochter als Zeichen ihrer Zuneigung zwei wertvolle Schmuckstücke geschenkt, einen großen, in Gold gefaßten Smaragd und einen Rubin, der le Rubby de la Guenoille genannt wurde und den Anna später an ihren ăltesten Sohn weitergab. Ende November 1573 tătigte die Dame von Montargis eine Schenkung von $\mathbf{5 0} \mathbf{0 0 0}$ Livres zugunsten der Tochter, auszuzahlen ein Jahr nach ihrem Tod ${ }^{96}$. Aus der Zeit unmittelbar nach Renées Ankunft in Orléans beschreibt der englische Gesandte eine Szene großer Vertrautheit beim alltåglichen Umgang der beiden Damen: Wăhrend Throckmorton mit der Herzoginwitwe von Ferrara in eine Unterhaltung vertieft war, offnete sich die Tür und in den Raum trat Anna, die sich sofort wie selbstverständlich in das Gesprä́ch mischte ${ }^{97}$. Wie beunruhigt schließlich die Protestanten von dem engen Verhältnis Renées zu ihrer von einigen als radikale Katholikin angesehenen Tochter waren, geht aus einem Brief hervor, in dem Théodore de Bèze die Furstin zur Mäßigung ermahnte: L'affection maternelle est bonne et saincte d'elle mesmes. Car Dieu en est l'autheur. Mais je vous supplie, Madame, de bien regarder à la regler et mesurer par les commandemens de la premiere table ${ }^{98}$.

\section{Der Prozeß gegen die französische Krone}

Verbunden fuhlten sich Anna und ihre Mutter nicht zuletzt des Prozesses wegen, den sie gemeinsam gegen die franzősische Krone fuhrten. Als Tochter von Ludwig XII. und Anne de Bretagne war Renée der Ansicht, Anspriche auf einen Teil des patrimoine des Hauses Orléans und der Bretagne zu haben,

95 Anna d'Este an Renée de France, o.D. (Sept. 1572), in: PoIZAT, Princesse de Clèves, S. 112. Das Wort in Klammern wurde von mir anhand BnF, Fr. 3230, fol. 4r korrigiert und die Satzzeichen angepaßt. Vgl. Jean-Louis BOURGEON, Charles IX devant la SaintBarthélemy, Genf 1995, S. 141, der den Brief auf den 18. September datiert.

${ }^{9}$ Schenkung von 50000 l.t. von Renée de France an Anna d'Este, 29. Nov. 1573, ratifiziert am 24. Juli 1574, in: AST (Cast.), Int., PGN, cat. 5, m. 8, n. 9-10. Lucrezia und Leonora erhielten zur gleichen Zeit jeweils dieselbe Summe, Luigi erhielt 10000 l.t. Zu dem Schmuckstück vgl. die Schenkungsurkunde vom 15. Juni 1555, in: Ibid. m. 4. n. 2; Inventaire des bagues.

${ }^{97}$ Nicolas Throckmorton an Elisabeth I., 10. Jan. (1561), Orléans, in: Calendar Elizabeth, 1865, S. 490.

${ }^{98}$ Théodore de Bèze an Renée de France, o.D. (Ende 1566), in: Théodore de BÈZE, Correspondance, Bd. 7, hg. v. Hippolyte AUBERT u.a., Genf 1973, S. 294. 
und so richtete sie wiederholt Gesuche an den König, damit dieser ihren Forderungen hinsichtlich der biens meubles, immeubles et patrimoine privé de son père et mère entspräche ${ }^{99}$. Doch die Dame von Montargis wußte, daß ein langwieriger Proze $B$ mit ungewissem Ausgang besser und ausdauernder von ihrer Tochter geführt würde, da Anna die Verfahrensweise der königlichen Gerichte kannte und bei der Verfolgung des Mordes an ihrem ersten Gemahl durch juristisches Talent aufgefallen war. Und so überließ Renée der Herzogin von Nemours alle Rechte, die ihr innerhalb und außerhalb des Königsreichs gehörten oder gehören könnten, ausgenommen ihre Ansprüche auf die Bretagne, und erteilte die Vollmacht, in ihrem Namen mit Karl IX. über das ihr Zustehende zu verhandeln ${ }^{100}$.

Die Herzogin von Nemours begann nun mit der Suche nach alten Papieren, mit deren Hilfe die Rechtmäßigkeit ihrer Ansprüche bewiesen werden könnte. Obwohl vom Hof, wie Renée ihrem Sohn später erzählte, sofort ein Bote in die Bretagne geschickt worden sei, der bei den dortigen Notaren alle diesbezüglichen Schriftstücke heraussuchen und verbrennen ließ, sollte es Anna doch gelingen, eine Urkunde zu finden, in der König Ludwig das Recht auf die Nachfolge gleichmäßig auf seine beiden ältesten Kinder verteilt hatte ${ }^{101}$. Daraufhin formulierte die Prinzessin ein Gesuch, in dem sie die Hälfte der duchéz, terres et seigneuries forderte, die einst ihrem Großvater gehört hatten, eine Forderung, welcher der procureur général des Königs nicht widerspruchlos entgegenkommen wollte, auch nicht, nachdem Renée selbst noch einmal gebeten hatte, que les donations et dispositions par elle faictes à ladite dame duchesse de Nemours sa fille soient declarées bonnes et vallables ${ }^{102}$. Als Anna nach aufmerksamer Lektüre des Ehevertrages ihrer Großeltern herausfand, daß Renée als zweiter Tochter außerdem die gesamte Bretagne zustand, konnte der König ihre Forderungen nicht länger ignorieren. Zwar hatte Renée anläßlich ihrer Heirat mit Ercole auf alle Ansprüche auf das elterliche Erbe verzichtet, doch war die Verzichterklärung von ihr niemals eigenhändig unterzeichnet worden, da sie zum Zeitpunkt der Eheschließung minderjährig war und ihr Schwiegervater später den Vertrag nicht wie vereinbart hatte ratifizieren lassen. Die Liste dessen, was Renée folglich zustand, mußte für Karl und seinen Hof beängstigend klingen: le duché de Bretaigne entier et la moictie ou aultre

\footnotetext{
${ }^{99}$ Gesuch von Renée de France an Karl IX., 6. Sept. 1568, in: BnF, Fr. 18709, fol. 543r.

${ }^{100}$ Vollmachten von Renée de France für Anna d'Este, 11. Dez. 1569, in: AST (Cast.), Int., PGN, cat. 5, m. 7, n. 4; Schenkung von Renée aller ihrer Rechte und Ansprüche an Anna, 29. Okt. 1568; Akzeptierung der Schenkung durch Anna, 9. Jan. 1569; nochmalige Bestätigung der Schenkung, 11. Dez. 1569, in: Ibid. n. 1, 3; Registrierung der Schenkung im châtelet von Paris, 9. Jan. 1569, in: AN, Y 109, fol. 263v.

${ }^{101}$ Alessandro Fiaschi an Alfonso d'Este, 18. Febr. 1575, Paris, in: ASM, Canc. duc., Amb. Francia 61.

${ }^{102}$ Gesuche von Anna d'Este und Renée de France an den procureur général des Königs, 2. u. 29. Sept. 1569, in: BnF, Fr. 18709, fol. 539r, 535r.
} 
portion contingente de touttes les autres terres de la maison d'Orléans et de Bretaigne [...], la moictié desdits meubles et deniers qui sont quasi inestimables Et le dot ou appennage accoustumé d'estre donné aux filles de France ${ }^{103}$.

Kurz vor Weihnachten 1570 fanden die Parteien zu einer Einigung. Renée ratifizierte ihren Ehevertrag und verzichtete damit auf ihre Ansprüche auf das Erbe der Eltern, dafür überließ der König ihr und ihrer Tochter das Herzogtum Nemours, welchem er gleichzeitig den Status der pairie verlieh, sowie Land und Herrschaft von Montargis. Als Apanage wurden der Königstochter Chartres, Gisors und Gien zugesprochen. Noch am selben Tag tätigte Renée eine Schenkung zugunsten ihrer Tochter. Montargis ging nun endgültig in den Besitz der Herzogin von Nemours über, und Renée gab an, diesen Schritt getan zu haben,

en consideration des grans fraitz et continuelles poursuittes que ladite dame Duchesse de Nemours a faictes et fait encores par chacun jour et pourra faire sy apres pour parvenir a lemologation de laccord et transaction faicte par ladicte dame Duchesse de Ferrare et elle avec le Roy [... et] pour la bonne amour et affection quelle luy porte et aux siens, et pour la recompenser des paines, labeurs fraitz et continuelles poursuittes; par elle faites et quelle pourra faire sy apres ${ }^{104}$.

Nur der Herzog von Ferrara, obwohl nach eigenen Worten aulcunement fasché ne contristé, fühlte sich übergangen und erwog, gegen diese Verträge vorzugehen ${ }^{105}$. In einer schriftlichen Erklärung versuchte Renée daraufhin, die Transaktion mit dem König und die Schenkung an Anna vor ihrem Sohn zu rechtfertigen. Auf den großen finanziellen Aufwand, den seine Schwester und sie selbst betrieben hätten, verweist die Königstochter in diesem Papier sowie auf die Tatsache, daß sie beide gemeinsam, und Anna oft allein viele Male persönlich vor dem König und seinem Rat erschienen seien. Vor allem zwei Dinge aber hätten zum Zustandekommen der Transaktion beigetragen: le soin et diligence dont elle [Anna] a use a recouvrer les tittres et papiers qui nous estoient incongneuz et emploie le credit quelle et les siens avoient envers les Seigneurs estans pres leurs Magestez et en leur conseil sans lesquelles choses jamais ce contract ne fut passe ${ }^{106}$. Doch Alfonso stand nicht allein mit seiner

${ }^{103}$ Transaktion zwischen Karl IX. auf der einen sowie Renée de France und Anna d'Este auf der anderen Seite, 23. Dez. 1570, in: MÜNCH (Hg.), Denkwürdigkeiten, S. 331. Ein zeitgenössischer Druck des Dokuments in: AST (Cast.), Int., PGN, cat. 5, m. 8, n. 5. Bei den meubles et deniers handelte es sich um die Hälfte von plusieurs biens meubles precieulx bagues et joyaulx [...] Et oultre grandes sommes de deniers jusques a cinq milions dor.

${ }^{104}$ Schenkung von Renée de France an Anna d'Este, o.D. (23. Dez. 1570), in: MƠNCH (Hg.), Denkwürdigkeiten, S. 41, 43; Transaktion zwischen Karl IX. auf der einen sowie Renée de France und Anna d'Este auf der anderen Seite, 23. Dez. 1570, in: Ibid. S. 343f.

${ }^{105}$ Forderungen von Alfonso d'Este an Renée de France, o.D. (1571), in: ASM, Casa 334. Vgl. das Gutachten französischer Juristen für Alfonso d'Este, o.D. (1571), in: Ibid. Nr. 333.

${ }^{106}$ Renée de France, Lestat auquel sont mes affaires pour bailler a mon fils Monsieur le Duc de Ferrare, o.D. (Anfang 1571), in: MÜNCH (Hg.), Denkwürdigkeiten, S. 305-311, Zitat 
Vermutung, Renée und Anna hätten sich betrügen lassen. Brantôme drückt eine ähnliche Meinung aus:

$D$ 'avantage, quel tort tient on à madame de Nemours, fille de madame de Ferrare, en partie heritiere de la duché de Bretaigne! Vrayement, ell'en a une belle part! pour tout pottage, ell'est madame de Montargis; c'est bien loin d'avoir la moictié de Bretaigne, qui vaut quinze cens mill' escuz et plus de revenu ${ }^{107}$.

Auch wenn der procureur général Nemours und Montargis als deux fleurons de la couronne bezeichnete, war sich die Herzogin des weitaus größeren Wertes der Bretagne bewußt und auch der Tatsache, un bien incomprehensible pour un bien peu eingetauscht zu haben ${ }^{108}$. Doch Anna zog den Spatzen in der Hand der Taube auf dem Dach vor, und ihre Kritiker bedachten nicht, daß der Vertrag noch nicht vom Parlament ratifiziert, das Verfahren somit noch nicht beendet war und viel Zeit vergehen konnte, bis die beiden Damen von dem ihnen Zustehenden profitieren konnten. Tatsächlich versuchte der procureur général, die Ratifizierung zu verhindern, so daß Renée, ihre Tochter und ihr Schwiegersohn wieder viel Zeit bei Hofe verbringen, Schriftstücke zusammentragen und Gesuche einreichen mußten. Und das, obwohl Karl IX. seinem Parlament die Ausfuhrung der Transaktion zumindest par provision geboten hatte. Sein Nachfolger sollte den Vertrag dann zwar anerkennen, doch aus einem Brief Annas an ihre Mutter ist zu ersehen, daß der Streit auch im Mai 1575 , einen Monat vor Renées Tod, noch nicht beigelegt war $^{109}$.

\section{Erbschaftsstreitigkeiten I: Die Hinterlassenschaft der Mutter}

Dies war nicht das einzige Verfahren, welches Anna in jenen Jahren beschäftigte. Sie unterstutzte ihren Gemahl bei seinem Vorgehen gegen Marie de Bourbon, Herzoginwitwe von Longueville, welcher Jacques vorwarf, ihn um einen Teil seines Erbes gebracht zu haben. Dabei verließ sich der Herzog auf

S. 310. Vgl. Anna d'ESTE, Memorandum für Alfonso d'Este, den Streit um das Erbe der Mutter betreffend, o.D. (Apr. 1577), in: ASM, Canc. duc., Cart. prin. est. 1459/23: le quale donationi sono state fatte alla predetta Madama di Nemours cosi per cagione della poca dota ch'ella ha havuto da casa sua come anche (la verità è) [... per] la sua diligenza et prosecutione $[e]$ i serviti di detti suoi mariti et figli.

${ }_{107}^{10}$ BRANTÓME, Euvres complètes, S. 191.

${ }^{108}$ Factum pour Madame la Duchesse de Nemours, fol. 21v.

109 Anna d'Este an Renée de France, 9. Mai 1575, in: BnF, Fr. 3423, fol. 35r. Vgl. Karl LX. an die Mitglieder des Pariser Parlaments, o.D. (1571), in: MÛNCH (Hg.), Denkwürdigkeiten, S. 317-319; Gesuch von Renée de France an Heinrich III., die Ausfuhrung der Transaktion vom 23. Dez. 1570 betreffend, o.D. (1574), in: AST (Cast.), Int., PGN, cat. 5, m. 8, n. 4. Heinrich III. hatte die Transaktion am 11. Dez. 1574 bekrtiftigt, wann jedoch das Parlament zur Ratifizierung schritt, ist unklar. Heinrich IV. bestatigte den Vertrag am 11. Jan. 1596, in: ASM, Canc. duc., Cart. prin. est. 1458/22. 
die juristischen Fähigkeiten seiner Gattin und erteilte ihr plain pouvoir, puissance et authorité. Tatsächlich sollte das Pariser Parlament ein vorläufiges Urteil zugunsten der Kläger sprechen, was den Herzögen von Nemours eine in ihrer Höhe nicht zu verachtende jährliche Rente einbrachte ${ }^{110}$.

Mit dem Tod von Renée de France am 15. Juni 1575 kam ein weiterer juristischer Streitfall auf Anna zu. Am Tag nach ihrer eigenen Ankunft in Montargis traf auch der Botschafter des Herzogs von Ferrara dort ein, welcher die Ansprüche seines Herrn auf das mutterliche Erbe zu vertreten hatte ${ }^{111}$. Bevor jedoch an die Exekution des Testaments gedacht werden konnte, galt es fur die Prinzessin, Renées Wünsche hinsichtlich des Begräbnisses und der Versorgung ihres Gefolges zu erfullen. Daneben hatte Anna sich um die Sicherung von Ort und Schloß zu kümmern, denn der König verließ sich darauf, daß repos, sureté et transquilité eingehalten würden ${ }^{112}$. Luigi d'Este, der sich in der Nahe von Senlis in einer seiner Abteien aufhielt, verspürte nicht die geringste Lust, nach Montargis zu reisen und die Schwester bei der Bewältigung der Aufgaben zu unterstiutzen, obwohl die Mutter sie gemeinsam zu Testamentsvollstreckem bestimmt hatte. Gelangweilt verwies der Kardinal auf die Nichtigkeit des Anlasses: Wenn er Anna selbst einen Gefallen tun könnte, stiege er sofort aufs Pferd, aber sie sorge sich ja nur um den Leichnam der Mutter und um deren Gefolge. In Wirklichkeit ging es natürlich um viel mehr. Es ging um den beweglichen Besitz der Königstochter, welchen Jacques gegen die Summe von 10000 Livres furr seine Gemahlin erstand, vor allem aber ging es um ihre Einkünfte aus Grund und Boden, in erster Linie um Montargis ${ }^{113}$. Testamentarisch hatte Renée ihrer ältesten Tochter das Nutzrecht an chasteau, terre et seigneurie de Montargis überlassen, obwohl der Ort mit Ratifizierung der Transaktion vom 23. Dezember 1570 automatisch in Annas Besitz übergehen würde. Deren Advokaten stellten dann auch fest, das Testament stunde im Gegensatz zu ihren Rechten, und wer es aufgesetzt habe, habe ihr einen

${ }^{110}$ Die Rente betrug 10000 Crowns: Henry Cobham an William Cecil, 6. Sept. 1583, Paris, in: Calendar Elizabeth, 1914, S. 104. Das Zitat: Testament von Jacques de Savoie, 6. Juli 1580, ratifiziert am 15. Apr. 1585, in: AST (Cast.), Int., PGN, cat. 2, m. 13, n. 4. Anfang der 1570er Jahre fuhrte Anna außerdem einen Prozeß gegen Robert de Ligny, bei dem es um die Unterschlagung von 4000 l.t. ging: Ibid. cat. 5, m. 8, n. 3.

${ }^{111}$ Ercole Strozzi an Guglielmo Gonzaga, 16. Juni 1575, Paris, in: FonTANA, Renata di Francia, Bd. 3, S. 303. Fontana irtt bei der Transkription, wie der Vergleich mit ASMan, AG 657, fol. 302v zeigt: »Havuta questa nova M. $^{\text {or }}$ [tatsächlich aber $M^{\text {ma }}$ ] di Nemours et il cav. Fiasco Ambasciatore del sig. Duca di Ferrara sono andati a Montargis«.

${ }^{112}$ Heinrich III. an Anna d'Este, 19. Juni 1575, Paris, in: HENRI III, Lettres, Bd. 2, S. 177.

${ }^{113}$ Luigi d'Este an Anna d'Este, 22. Juni 1575, Chaalis, in: BnF, Fr. 3423, fol. 40r; Übereinkunft zwischen Anna d'Este und Jacques de Savoie auf der einen sowie Alessandro Fiaschi, Gesandter des Herzogs von Ferrara, auf der anderen Seite, Renées beweglichen Besitz betreffend, 9. Juli 1575, in: ASM, Casa 333. 
schlechten Dienst erwiesen ${ }^{114}$. Auch der Herzog von Ferrara, der Anspruch auf Montargis erheben zu können glaubte, hatte Juristen konsultiert. Die waren der Ansicht, Alfonso könne das Erbe seiner Mutter beschlagnahmen lassen, eingeschlossen tous les biens, meubles et immeubles, lectres, tiltres, pappiers. Vorsichtshalber hatte sein Botschafter aber noch nachgefragt, ob das Testament einer Häretikerin in Frankreich Gültigkeit beanspruchen könne. Es konnte ${ }^{115}$.

Anders als bei den bisher von der Herzogin von Nemours geführten Prozessen handelte es sich diesmal um einen privaten Streitfall, zu dessen Lösung weder das Pariser Parlament noch der Rat des Königs bemüht wurde, sondern allein die Vertreter der Parteien. Außerdem ging Anna zum ersten Mal gegen ein Mitglied der eigenen Familie vor. Dies führte dazu, daß die Verhandlungen mit weitaus mehr persönlichem Engagement der Beteiligten und mit gröBerer Polemik geführt wurden, sich die Streitenden wiederholt gegenseitig vor vollendete Tatsachen stellten und neben den Juristen auch die Geschwister zum Zwecke der Vermittlung eingesetzt wurden. So schrieb etwa Anna dem jüngeren Bruder, als dieser im Frühjahr 1577 nach Italien reiste, sie habe mehr Vertrauen in ihn und seine Verhandlungen mit dem Herzog, che in qual si voglia altra cosa. Als Jahre später immer noch keine Einigung erzielt war, schaltete der Kardinal zusätzlich die Schwester Lucrezia in die Unterredungen ein, worüber sich Anna bien fort aise zeigte, da sie von deren Freundschaft und Wohlwollen überzeugt war und wußte, daß Lucrezia alles daransetzen würde, den Konflikt aus der Welt zu schaffen. Ihre Hoffnungen in die Mission des Bruders waren groß gewesen, und nun schien sie ihm die Schuld an den unendlichen Verzögerungen geben zu wollen: Seine älteste Schwester, ist aus einem Brief des Kardinals zu erfahren, si duole assai di me, gerade so, als wäre er derjenige, der eine Einigung verhindere. Der Herzog von Nemours verdächtigte währenddessen die Advokaten und Rechtsberater, les gens de robbe longue, presque tous ennemis du bien et repoz commung, das Verfahren in die Länge $z u$ ziehen ${ }^{116}$. So warfen sich die Beteiligten gegenseitig vor, einen raschen Abschluß verhindern zu wollen. Als die Prinzessin dann erfuhr, dem Bruder sei zugetragen worden, sie selbst wünsche einen langwierigen

${ }^{114}$ Testament von Renée de France, 22. Okt. 1573, in: Gaston BONET-MAURY, Le testament de Renée de France, duchesse de Ferrare (1573), in: Revue historique 46 (1891) S. 73-82, Zitat S. 78; Jérôme (?) de MONTHOLON, Pierre VERSORIS, Konsultation für Anna d'Este, den Streit mit Alfonso d'Este um Montargis betreffend, 2. Juli 1575, in: AST, Int., PGN, cat. 5, m. 8, n. 13.

${ }^{115}$ Gutachten der Advokaten Fontenay und Villecoq tiber die Transaktion vom 23. Dez. 1570 für Alfonso d'Este, o.D. (1571), in: ASM, Casa 333; Alessandro Fiaschi an Alfonso d'Este, 25. Juni 1575, Montargis, in: FONTANA, Renata di Francia, Bd. 3, S. 306.

${ }^{116}$ Anna d'Este an Luigi d'Este, o.D. (Apr. 1577), 22. Juli 1581, in: ASM, Canc. duc., Cart. prin. est. 1459/23; Luigi d'Este an Lucrezia d'Este, 15. Nov. 1581, in: Ibid. Nr. 1547/67; Jacques de Savoie an Alfonso d'Este, 22. März 1583, Moncalieri, in: Ibid. Nr. 1457 A/21. Vgl. Lucrezia d'Este an Luigi d'Este, 11. Okt. u. 25. Nov. 1581, Ferrara, in: Ibid. Nr. $1467 / 10$. 
Prozeß, um nach Alfonsos Tod allein vom Erbe der Mutter profitieren zu können, war sie fassungslos und dementierte in einem wütenden Schreiben die Vorwürfe als discours et yugemant sy meschant et perverty, tant absurde et sy eslongné de la rayson et de la veryté. Der Vorgang zeigt, an welchem Punkt die Geschwister nach Jahren des Kleinkriegs angelangt waren ${ }^{117}$.

Erst im Mai 1583, acht Jahre nach dem Tod der Mutter, kamen die Geschwister zu einer Einigung. Alfonso erhielt Montargis, doch wurde der Herzogin von Nemours das lebenslange Nutzrecht zugesprochen, das nach ihrem Tod an den Besitzer zurückfallen sollte. Der garantierte der Schwester dafür die 50000 Livres, welche Renée ihr einst geschenkt hatte, eine Summe, von der nach Abzug von Annas Schulden beim Bruder immerhin fast $35000 \mathrm{Li}$ vres übrigblieben. Tatsächlich sollten zukünftig die den Ort betreffenden Verträge vom Herzog von Ferrara oder dessen Agenten ratifiziert werden ${ }^{118}$. Nun hätte eigentlich Ruhe einkehren können im Verhältnis der Geschwister, doch der Friede währte nicht lange. Drei Jahre später, als die im Schloß von Montargis befindlichen Papiere verteilt werden sollten, von denen laut Abmachung die das Nutzrecht betreffenden Anna zustanden, alle anderen aber Alfonso, kam es zwischen den Vertretern der Parteien zu neuerlichen Unstimmigkeiten, doch wurde auch dieser Konflikt gelöst ${ }^{119}$. Für die Prinzessin waren diese Auseinandersetzungen von großer Bedeutung gewesen, sie hatte sich in ihrer Ehre verletzt und im Innersten getroffen gefühlt. Ho havuto carissimo che quelle poche differenze ch'erano fra noi si siano composte amorevolmente, bedankte sich Alfonso hingegen leichthin bei ihr, obwohl er um die Seelenqualen der Schwester wußte, hatte sie ihm doch mitgeteilt: $j$ 'ay tousiours eu continuellement cela sur le cour ${ }^{120}$.

\section{Erbschaftsstreitigkeiten II \\ Die Hinterlassenschaft des Bruders und der Schwester}

Kaum war die Auseinandersetzung um die Hinterlassenschaft der Mutter beendet, kam schon der nächste Erbschaftsstreit auf die Geschwister zu. Ende

${ }^{117}$ Anna d'Este an Alfonso d'Este, 4. Juni 1582, Verneuil, in: ASM, Canc. duc., Cart. prin. est. 1458/22.

${ }^{118}$ Vertrag zwischen Anna und Alfonso d'Este, das mütterliche Erbe betreffend, 11. Mai 1583, ratifiziert am 8. Sept. 1583, in: ASM, Casa 334. Vgl, den Vertrag zwischen Anna d'Este sowie Pierre Menard und Thomas Guyon, 4. Sept. 1595, in: LELOUP, Anne d'Este, S. 64

${ }^{119}$ Anna stimmte zu, zur Sicherung von Alfonsos Herrschaft über Montargis die im Schloß befindlichen Urkunden an ihn auszuliefern und die Lehnseide in Zukunft auf ihn schwören zu lassen, vgl. ihre schriftliche Zusicherung vom 24. April 1587, in: ASM, Casa 334.

${ }_{120}$ Alfonso d'Este an Anna d'Este, 19. Mai 1587, Comacchio, in: BnF, Fr. 3418, fol. 32r; Anna d'Este an Alfonso d'Este, 29. Okt. 1586, Paris, in: ASM, Canc. duc., Cart. prin. est. $1458 / 22$. 
Dezember 1586 starb der Bruder Luigi. Der Herzogin von Nemours hatte er zweitausend Écus jăhrliches Einkommen vermacht, die Schulden, welche der König im Laufe der Jahre bei ihm angehäuft hatte sowie alles Vermögen, das er in Frankreich besaß. Nach Annas Tod sollte dieses Erbe zur Hälfte an die männlichen Kinder aus ihrer ersten Ehe, zur anderen Halfte an die aus zweiter Ehe ausgezahlt werden. Aus diesem Grunde ließ die Prinzessin den Bruder Alfonso bitten, ne trouver mauvais si elle faict exacte demande de ce qui peult estre comprins audit legs, da sie alle Forderungen nur im Namen ihrer Kinder stellte $^{121}$. Im gleichen Zuge machte Anna Ansprüche auf die Hinterlassenschaft der Schwester Leonora geltend, die im Februar 1581 verstorben war und ihre beiden Brüder zu gleichen Teilen als Universalerben eingesetzt hatte. $\mathrm{Da}$ in Frankreich Frauen ebenso erbberechtigt seien wie Mănner, so die Argumentation, stehe Leonora ein Fünftel der französischen Hinterlassenschaft des Vaters zu, welches sie wiederum zur Hălfte dem Bruder Luigi vermacht habe, so daß sich Annas Forderungen auf eine Summe von 220000 Livres beliefen ${ }^{122}$.

Ende des Jahres 1588 begannen die Verhandlungen konkrete Formen anzunehmen, und es ist interessant zu sehen, wie schnell sich die Geschwister trotz, oder vielleicht gerade wegen der umwälzenden Ereignisse im Leben der Herzogin einig wurden. Denn bereits Anfang Juni des folgenden Jahres fand in Paris eine merkwürdige Versammlung statt, bei der sich Anna und ihre Tochter Catherine sowie ihre Schwiegertöchter, die Herzoginnen von Guise und von Mayenne, welche Sohn und Gatten vertraten, mit Alfonsos Repräsentanten auseinandersetzten. Die Damen hatten hoch gepokert, der Anspruch auf eine angebliche franzősische Hinterlassenschaft Leonoras etwa war absurd, doch am Ende erlangten sie beträchtliche Zugeständnisse seitens der Vertreter des Herzogs, denen sie im Laufe des Gesprächs gehörig zugesetzt zu haben scheinen: ceste dispute, schrieb einer von ihnen nach Ferrara, n'estoit pas sans difficulté. $\mathrm{Zu}$ einer Einigung seien sie nicht ohne Mühe gelangt, heißt es in dem Bericht weiter, par ce qu'il sembloit que ces princesses eussent esté mises en opinion qu'on leur deust laisser tout. Die ungunstigen Bedingungen der Abmachung wurden von Alfonsos Juristen daher besser dargestellt als sie in

121 Testament von Luigi d'Este, 25. Febr. 1585, in: Francesco SAVERro SENI, La Villa d'Este in Tivoli. Memorie storiche tratte da documenti inediti, Rom 1902, S. 249; Ce sont les droictz que Madame la Duchesse de Genevois et de Nemours pretend avoir sur les biens de feu Monseigneur l'Illustrissime et Reverendissime Cardinal d'Est son frère, o.D. (1588), in: ASM, Casa 358.

${ }^{122}$ Forderungen von Anna d'Este, das Erbe der Schwester Leonora betreffend, o.D. (1588), in: MûNCH (Hg.), Denkwirdigkeiten, S. 357-368. Leonora hatte Anna un diamonte in punta ch'è in un scattolino d'auorio vermacht, um dessen Auslieferung diese den Bruder bat, da sie ihn in Erinnerung an die Schwester tragen wolle: Testament von Leonora d'Este, 2. Dez. 1573, in: CAMPORI, SOlerTI, Studi, S. 155; Anna d'Este an Luigi d'Este, 23. Mai (1581), Blois, in: ASM, Canc. duc., Cart. prin. est. 1459/23. 
Wirklichkeit waren: Der Text des Papiers sei in einem Ton gehalten, qui conserve à Son Altesse l'honneur et la révérence, sein Anteil am Erbe sei nect et clair, das heißt, nicht von Schulden belastet und daher de grande et notable valeur, kurz: Ce qui demeure à Son Altesse est le meilleur et le plus clair de la succession. Auch Anna versuchte, den Wert der französischen Besitztlumer des Kardinals herunterzuspielen, indem sie behauptete, que ce qui est par desà ne soyt pas grand chose ${ }^{123}$. Laut Vertrag verzichteten die Damen auf ihre Anspruche bezüglich der Hinterlassenschaft Leonoras und auf die jährliche Auszahlung der zweitausend Écus, dafür erhielten sie den Rest der französischen Hinterlassenschaft des Kardinals, während sich Alfonso mit einer Rente von rund fünfhundert Écus, einem der kleineren Besitztümer des Bruders sowie seinen Möbeln und dem Silbergeschirr zufriedengeben mußte. Doch dem Herzog schien bewußt zu sein, worauf er verzichtete, denn selbst sechs Jahre später hatte er den Vertrag noch immer nicht ratifiziert ${ }^{124}$.

\section{Strategien der Prozeßführung}

Wie nervenaufreibend diese Verhandlungen für die Prinzessin waren, geht aus einer Vielzahl von Briefen hervor, in denen sie wegen ihrer affaires d'importance et de grans solicitude et paines bedauert wird. So bemerkte ihr altester Sohn, Anna würde sich ihrer Angelegenheiten jusques à l'estremyté widmen, er sehe sie sy affligée et annuiée que, sur mon honneur, il y a un mois que l'euil ne luy seche. Mitverantwortlich für den Trubsinn der Herzogin war die Notwendigkeit, sich bei Hofe oder in Paris aufhalten zu müssen, wo ihre Angelegenheiten verhandelt wurden, während Jacques sich auf einem seiner Schlösser befand. Der Mutter gegenüber beklagte Anna sich oft, seit sie in Paris sei, habe sie nichts anderes getan als aller solliciter de tous costez, et de faict mon sejour est icy sy necessaire que je n'en partirois, encores qu'il y ayt assez longtemps que je n'aye veu Monsyeur mon mary, während Henri dem Herzog von Nemours versicherte, wie wichtig der Aufenthalt seiner Mutter in der Hauptstadt sei ${ }^{125}$.

${ }^{123}$ Bericht von Simon Marion an Alfonso d'Este, die Verhandlungen über Luigis Erbe betreffend, o.D. (Juni 1589), in: ASM, Casa 358; Anna d'Este an Alfonso d'Este, 10. Juni 1589, Paris, in: ASM, Canc. duc., Cart. prin. est. 1458/22.

${ }^{124}$ Vertrag über die französischen Hinterlassenschaften von Luigi d'Este, 8.-9. Juni 1589, in: AST (Cast.), Int., PGN, cat. 5, m. 9, n. 10; Anna d'Este an Alfonso d'Este, 30. Nov. 1595, Lagnieu, in: ASM, Canc. duc., Cart. prin. est. 1458/22. Wann Alfonso die Abmachungen ratifizierte, ist unklar, der entsprechende Entwurf bzw. die Kopie in: ASM, Casa 334, ist nicht datiert.

${ }^{125}$ Renée de Lorraine an Anna d'Este, 8. Mai 1571, Reims, in: BnF, Fr. 3228, fol. 28r; Henri de Lorraine an Jacques de Savoie, o.D. u. (Ende 1583), in: BnF, Fr. 3391, fol. 1r, 5r; Anna d'Este an Renée de France, o.D., in: BnF, Fr. 3230, fol. 17r. 
Wie auch anläßlich der Verfolgung der Verantwortlichen für den Mord an François war die persönliche Präsenz für den glücklichen Ausgang eines Prozesses notwendig, und wenn die Beteiligten selbst verhindert waren, mußte zumindest ein Vertreter entsandt werden. So war Renée von ihrer Tochter gebeten worden, da sie selbst aufgrund ihrer Krankheit dem Hof nicht folgen könne, jemanden zu schicken, qui vienne sollissiter ${ }^{126}$. Langwierig waren die Verhandlungen immer, vor allem die gegen den König, da es hier um den Bestand des Territoriums der französischen Krone ging. Les affaires sont allees en si grand longueur et tout de contractz faictz et deffaiz [...] et tout cela a este Rompu et brusle et deffaict et reffait plusieurs foys, versuchte etwa Renée ihrem Sohn die Schwierigkeiten des Verfahrens gegen die Krone zu erklären. Diejenigen, die an dem Text der Transaktion gearbeitet hätten, estoient tran[s]portez de crainte, beschreibt sie die Anspannung, unter der die Beteiligten standen, und die Nervosität ihres Advokaten anläßlich dessen Plädoyer vor Karl IX. und seinem Rat: ie laye veu tembler et de voix et de Corps en la presence du Roy et de tout le Conseil, während sie selbst gestützt werden mußte ${ }^{127}$. Doch eine Alternative gab es nicht, denn letztlich ging kein Weg am Herrscher vorbei, auch nicht in weniger schwerwiegenden Fällen. Anna hatte dies erkannt und ihre Strategie danach ausgerichtet. So versuchte sie nicht nur in dem Verfahren gegen Marie de Bourbon mittels der Königinmutter das Wohlwollen Heinrichs III. zu erlangen, auch während der Verhandlungen im Namen Renées war sie trickreich um die Aufmerksamkeit des Herrschers bemüht: Zwar hatte Katharina ihr verboten, dem Sohn einen bestimmten Vorschlag zu unterbreiten, doch machte die Prinzessin in dessen Gegenwart eine Anspielung und weckte so das Interesse des Königs, der daraufhin nicht locker ließ, bis Katharina ihrer Freundin zu sprechen befahl ${ }^{128}$.

Daruber hinaus hatten sich in den juristischen Verfahren jener Jahre bei der Herzogin von Nemours Kenntnisse angehäuft sowie Strategien und Handlungsweisen herausgebildet, von denen sie in der folgenden Zeit profitierte. $\mathrm{Da}$ sie etwa die Bedeutung einer sorgfaltigen Inventarisierung von wichtigen Urkunden erkannt hatte und großen Wert auf ein wohlgeordnetes Archiv legte, ist aus einer Reihe von Briefen zu ersehen, mit deren Hilfe Anna sich um die Wiedererlangung unterschlagener Papiere bemühte. Das Original des Ehevertrags ihrer Großeltern, das vielleicht wichtigste Dokument im Prozeß gegen die Krone, hatte sie sich con mezzo de suoi amici e non senza spesa besorgen können, sehr zum Erstaunen ihrer Mutter, die sich selbst wiederholt darum

\footnotetext{
${ }^{126}$ Anna d'Este an Renée de France, o.D., in: BnF, Fr. 3230, fol. 46r.

${ }^{127}$ Renée de France an Alfonso d'Este, 3. Jan. 1571, Montargis, in: FonTANA, Renata di Francia, Bd. 3, S. 222, 224.

${ }^{128}$ Katharina von Medici an Anna d'Este, 21. Juli 1583, Monceaux, in: MÉDICIS, Lettres, Bd. 8, S. 114; Renée de France an Alfonso d'Este, 3. Jan. 1571, Montargis, in: FonTANA, Renata di Francia, Bd. 3, S. 228.
} 
bemüht hatte ${ }^{129}$. Wenn ihre persönliche Präsenz erforderlich war, begab Anna sich auch in die Häuser ihrer Gegner, und die Wichtigkeit juristischer Konsultation seitens ihres Rates hatte die Prinzessin ebenso verstanden. Dessen Mitgliedern billigte sie im Laufe der Jahre immer größeren Einfluß zu, bis hin zu dem Punkt, daß sich ihre Verhandlungspartner über die langwierigen Verfahren beschwerten: li dottori di Madama sono stati divisi, erklärte Jahre später der Nuntius eine der hăufigen Verzögerungen, während sein Sekretär klagte: non mi è giovata nè diligenza, nè importunità ch'io habbia usata, ché sendo Madama per natura irresoluta, et dovendo sentir' il parer' di suoi avocati [...] una volta sola si son convenuti insieme et all'hora non si seppero risolver ${ }^{130}$.

Zu den im Laufe jener Prozesse entwickelten Strategien zählte auch die Pflege guter Beziehungen zu einflußreichen Fürsprechern bei Gericht und im königlichen Rat, wie etwa zu Simon Marion, mit dem Anna während der Streitigkeiten mit dem Bruder noch heftige Kämpfe ausgefochten hatte, der jedoch Jahrzehnte später, als Generalanwalt des Pariser Parlaments, zu ihren Klienten, dann auch zu ihrem Rat gehörte und fur dessen Anliegen sich die Prinzessin einsetzte. So unterstultzte sie ihn beispielsweise in seinen Bemühungen um eine päpstliche Dispens für die Enkelin Jacqueline Arnauld, die später berühmte Mère Angélique, die dann tatsächlich, als noch nicht Elfjährige, zur Äbtissin des Pariser Klosters Port-Royal gewählt werden sollte ${ }^{131}$. Außerdem unterhielt die Herzogin ein gutes Verhältnis zu den königlichen Ministern, über die sie Einfluß auf die Tagesordnung der Ratssitzungen zu nehmen versuchte. Kein Wunder, daß sie als Expertin angesehen und nicht selten um juristischen Rat gebeten wurde, wie etwa von jener Dame, die zu wissen wünschte, sy trouverez bonne la poursuite que je delibère faire faire à la chambre des usures ${ }^{132}$.

${ }^{129}$ Anna d'Este an ein Mitglied der Familie del Bene, Okt. 1600-Jan. 1601, Lyon, in: BnF, Fr. 20539, fol. 67r, 69r, 73r; Alessandro Fiaschi an Alfonso d'Este, 18. Febr. 1575, Paris, in: ASM, Canc. duc., Amb. Francia 61.

${ }^{130}$ Innocenzo del Bufalo und Vincenzo Ungarino an Pietro Aldobrandini, 11. Mai u. 2. Juli 1602, in: Correspondance du nonce en France Innocenzo del Bufalo, évêque de Camerino (1601-1604), hg. v. Bernard BARBICHE, Rom, Paris 1964, S. 292, 312.

${ }^{131} \mathrm{Vgl}$. den Hinweis auf Annas diesbezulgliches Schreiben, 5. Sept. 1601, in: Correspondance Bufalo, S. 176, und die Ausgaben für deus porcs aus s. ${ }^{r s}$ Milan et Marion im Rechnungsbuch 1591 von Anna d'Este, in: AST (Piave), ACP, Art. 806, par. 2, reg. 170, fol. 22v (Mai). $\mathrm{Zu}$ den Bereicherungen der "gens de robe«: Denis RICHET, Les liens de clientèle: l'exemple de la "robe « en France aux XVI et XVII ${ }^{e}$ siècles, in: Antoni MACZAK ( $\mathrm{Hg}$.), Klientelsysteme im Europa der Frühen Neuzeit, München 1988, S. 149-152.

${ }^{132}$ Anna d'Este an Pomponne de Bellièvre, 30. Aug. u. 19. Sept. o.J. (Anfang 17. Jh.), in: BnF, Fr. 15897, fol. 559r, 566r. Anna hatte sich schon kurz nach Bellièvres Entlassung durch Heinrich III. um den ehemaligen königlichen Minister bemüht: Olivier PONCET, Pomponne de Bellièvre (1529-1607). Un homme d'État au temps des guerres de religion, Paris 1998, S. 167f. Das Zitat: Henriette de La Noue an Anna d'Este, 22. Aug. o.J., Le Faou, in: BnF, Fr. 3397, fol. 85r. 
